Research Article

\title{
Reinforcement Effects of Isolation Piles on the Adjacent Existing Tunnel in Building Construction
}

\author{
Aijun Yao, ${ }^{1}$ Jian Lu $\left(\mathbb{D},{ }^{1}\right.$ Yanfei Guo, ${ }^{1}$ Jiantao Zhang $\mathbb{D}^{2,3}$ and Haifeng Guo $\mathbb{D}^{1}$ \\ ${ }^{1}$ College of Architecture and Engineering, Institute of Geotechnical and Underground Engineering, \\ Beijing University of Technology, Beijing 100124, China \\ ${ }^{2}$ China Academy of Building Research, Beijing 100013, China \\ ${ }^{3}$ CABR Foundation Engineering Co., Ltd., Beijing 100013, China
}

Correspondence should be addressed to Jian Lu; lj_beyond@sina.com

Received 4 April 2019; Revised 1 September 2019; Accepted 6 September 2019; Published 1 October 2019

Academic Editor: Georgios I. Giannopoulos

Copyright (C) 2019 Aijun Yao et al. This is an open access article distributed under the Creative Commons Attribution License, which permits unrestricted use, distribution, and reproduction in any medium, provided the original work is properly cited.

\begin{abstract}
Similar material model test and numerical simulation method were used to study the reinforcement effect of isolation piles on the existing shield tunnel structure in the adjacent building construction for analyzing foundation pit excavation and new building construction approaching existing shield tunnel engineering. The numerical simulation orthogonal experiment was used to optimize four isolation pile parameters. The conclusions were obtained as follows: (1) Isolation piles could share horizontal load of the soil at the rear side of the support structure and reduce horizontal displacement of the soil. As a result, maximum horizontal displacement of the tunnel structure and differences in horizontal displacement between the tunnel structure roof and the floor after foundation pit excavation and building loading were decreased. The horizontal displacement and torsional deformation of the tunnel structure toward the direction of the foundation pit were controlled, and the increase in internal forces of the transverse tunnel structure was also restrained. (2) At the elevation above the tunnel roof, the increase in burial depth of the isolation pile top slightly affected the reinforcement effect on the tunnel structure. The increase in burial depth of the isolation pile bottom could improve the reinforcement effect. Thus, burial depth of the isolation pile bottom should be properly increased in the engineering practice. The reduction in pile spacing could improve the reinforcement effect. Accordingly, pile spacing should be properly selected in the engineering practice. With the increase of diameter of the isolation pile, the reinforcement effect of isolation piles increased obviously. (3) Pile diameter had the greatest influence on the reinforcement effect of isolation piles, followed by burial depth of the pile bottom, pile spacing, and burial depth of the pile top. Orthogonal experiments indicated the following optimal parameter values: a pile diameter of $1.2 \mathrm{~m}$, a burial depth of the pile bottom of $2 \mathrm{H}$, a pile spacing of $1.6 \mathrm{~m}$, and a burial depth of the pile top of $0.75 Z$.
\end{abstract}

\section{Introduction}

Urban rail transit construction drives economic development along metro lines while relieving ground traffic jams. Several commercial, public, and residential construction projects are adjacent to shield tunnels in service. Foundation pit excavation and building construction adjacent to the existing shield tunnel will break through the original stress state of the subway tunnel and the soil. A series of complicated unloading-loading processes form due to foundation pit excavation and follow-up building construction, which can exert an important influence on the tunnel structure. Thus, scholars have studied deformation laws of the adjacent tunnel structure in the foundation pit excavation and corresponding control measures.

Deformation and internal force of the tunnel structure are usually theoretically calculated using various methods, such as the Pasternak foundation model, semiempirical method, semianalytical method, singular function method, and Galerkin method [1-5].

As for numerical simulation, scholars have analyzed influences of foundation pit excavation adjacent to the existing tunnel under 2D and 3D conditions and acquired tunnel structure deformation laws [6-12]. 
$\mathrm{Ng}$ et al. [13] conducted three-dimensional centrifuge tests to study the influence of foundation pit excavation on the existing tunnel and acquired influence degrees of different factors in the excavation process through the analysis of model test results.

Control measures of existing tunnel structure deformation in the adjacent foundation pit excavation include reduction in the influence caused by the construction process on the existing tunnel structure from the source, such as optimizing foundation pit excavation measures and taking foundation pit reinforcement measures to protect the tunnel structure [14-18]. In addition, isolation piles and walls can be constructed in the soil adjacent to the tunnel to reduce soil deformation around the tunnel and protect the tunnel structure. Zheng et al. [19] analyzed the working effect of isolation piles and thus acquired the relationships of working performance of isolation piles with pile spacing and length. Other scholars $[20,21]$ explored the influences of factors such as pile length and diameter on the reinforcement effect of the pile and provided further reference for design and construction of isolation piles.

Existing studies have investigated deformation laws of the adjacent tunnel structure due to foundation pit excavation and control measures. However, few of these works have paid attention to the reinforcement mechanism of isolation piles for the existing tunnel structure under unloading-loading effects of the building construction. Therefore, the reinforcement mechanism and effect of isolation piles on the existing tunnel structure under foundation pit excavation and building loading were studied using the similar material model test and numerical simulation methods. The transverse internal forces and deformation laws of the tunnel structure were obtained. A group of orthogonal experiments based on numerical simulation were carried out to simulate foundation pit excavation and building construction adjacent to the existing tunnel under different isolation piles and influencing factors for providing a certain reference for the selection of the reinforcement scheme.

\section{Reinforcement Mechanism of Isolation Piles and Influencing Factors in Foundation Pit Excavation}

In foundation pit excavation, the supporting structure will generate horizontal displacement deformation toward the foundation pit under active earth pressure at the rear side. Consequently, soil outside the foundation pit will generate the extrusion effect on the adjacent tunnel, and the tunnel structure will experience horizontal displacement toward the foundation pit. The internal forces of the tunnel structure also change under the extruding effect of the soil, which affects the safety of the tunnel structure. Therefore, reduction in horizontal displacement of the soil at the rear side of the supporting structure is a major research topic.

The isolation pile reinforcement method has been applied to actual engineering to reduce horizontal displacement deformation of the soil at the rear side of the supporting structure in foundation pit excavation. In this process, the soil at the rear side of isolation piles extrudes pile bodies. A horizontal miniature pressure arch is formed between isolation piles. Thus, soil pressure transfers to the isolation piles, and the soil pressure acting upon the supporting structure decreases. The effects of reduction in soil horizontal displacement and protection of the existing tunnel structure are ultimately realized.

Through engineering application and further development, existing isolation piles are divided into various layouts, such as double-row, single-row, and root piles [22]. The planar layout of isolation piles can be in different forms, such as linear, microarched, and broken line.

The reinforcement effect of isolation piles is influenced by various factors, such as pile length, pile rigidity, and pile spacing. Therefore, linearly arranged single-row isolation piles were used in this study to analyze the influences of burial depth of the isolation pile bottom, pile spacing, burial depth of the pile top, and pile diameter on the reinforcement effect on the existing tunnel structure.

\section{Similar Material Model Test}

3.1. Prototype Engineering and Test Scheme. A building construction project adjacent to the subway tunnel in Beijing is located in Chaoyang District, and the west side of the project is close to the subway tunnel in service. The tunnel is constructed using the shield method, and its outer edge is $5.10 \mathrm{~m}$ away from the west side of the basement in this project. The outer diameter of the shield tunnel is $6.0 \mathrm{~m}$, the lining segment thickness is $300 \mathrm{~mm}$, the material is C50 prefabricated concrete, and the segment ring width is $1.2 \mathrm{~m}$. The excavation depth of the foundation pit is $15.0 \mathrm{~m}$. The combined support pattern of "composite soil nailing wall + diaphragm wall + prestressed anchor cable" is adopted for the foundation pit excavation. Table 1 presents the physical and mechanical parameters of the soil at the engineering site.

In this study, the similar material model test of the reinforcement effect of isolation piles under actual construction conditions was carried out. The model test was divided into two engineering situations: with and without isolation pile reinforcement. The isolation piles were divided into two forms, namely, conventional- and buried-type isolation piles [19], depending on the difference in burial depth of the pile top. To study the reinforcement effects of isolation piles under the influence of different factors, four groups of the similar material model test were carried out with different values of burial depth of the pile top and pile spacing, as shown in Table 2 ( $Z$ is the burial depth of the tunnel axis and $D$ is the diameter of the isolation pile).

3.2. Determination of Similarity Coefficients. The dimensions of prototype engineering and model box were considered comprehensively following the similitude principle. To avoid the influence of boundary conditions on the test $[23,24]$ and satisfy the measurement accuracy simultaneously, the similarity coefficient of 15:1 was determined as the 
TABle 1: Physical and mechanical parameters of the soil.

\begin{tabular}{lcccccc}
\hline Stratum name & Thickness $(\mathrm{m})$ & Compression modulus $(\mathrm{MPa})$ & Poisson's ratio & $\begin{array}{c}\text { Unit weight } \\
\left(\mathrm{kN} / \mathrm{m}^{3}\right)\end{array}$ & $\begin{array}{c}\text { Cohesion } \\
\left(\mathrm{kN} / \mathrm{m}^{2}\right)\end{array}$ & $\begin{array}{c}\text { Internal friction angle }\left({ }^{\circ}\right) \\
\text { Miscellaneous fill }\end{array}$ \\
\hline Clayey silt I & 5.0 & 7.0 & 0.36 & 18.5 & 10 & 15 \\
Silty clay & 13.2 & 7.7 & 0.25 & 21.6 & 21 & 20.7 \\
Clayey silt II & 1.8 & 9.7 & 0.26 & 20.7 & 28.7 & 20.6 \\
Medium sand & 3.2 & 18.7 & 0.25 & 20.7 & 30 & 23 \\
Pebbles & - & 30.0 & 0.27 & 21.0 & 0 & 30 \\
\hline
\end{tabular}

TABLE 2: Similar material model test schemes.

\begin{tabular}{lcccc}
\hline Scheme number & Isolation pile form & Burial depth of the pile top & Pile spacing & Total load of the foundation pit $(\mathrm{kN})$ \\
\hline 0 & Without piles & - & - & 8.4 \\
1 & Conventional type & 0 & $2 D$ & 8.4 \\
2 & Buried type & $0.4 Z$ & $2 D$ & 8.4 \\
3 & Buried type & $0.4 Z$ & $3 D$ & 8.4 \\
\hline
\end{tabular}

prototype model in this model test, and the geometric similarity coefficient $N=15$.

3.3. Model Box and Strata Simulation. The model box had a size of $3 \mathrm{~m} \times 1 \mathrm{~m} \times 2 \mathrm{~m}$, and the model box is composed of seventeen standard components, four stiffening ribs, and three strengthened ring beams. The size of each standard component is $1 \mathrm{~m} \times 1 \mathrm{~m}$, which is made of a steel frame and organic glass. The model box is shown in Figure 1.

The strata were simulated by a similar material. The similar material was prepared using four materials, namely, river sand, iron powder, gypsum, and lime. River sand and iron powder were aggregates, and gypsum and lime were adhesives. Table 3 shows the similar material composition and matching ratio. Table 4 shows the parameters of prototype and model strata.

3.4. Simulation of Foundation Pit Supporting Structure and Measurement Scheme. The foundation pit supporting scheme in the model test was the same as that in prototype engineering, and the combined supporting scheme of "slope excavation + diaphragm wall + prestressed anchor cable" was adopted. The tunnel structure and diaphragm wall were simulated by an organic glass cylinder and plate, respectively, and the geometric similarity ratio was $15: 1$. The inner and outer diameters of the tunnel model were 360 and $400 \mathrm{~mm}$, respectively. The thickness, height, and length of the diaphragm wall were $50,1,000$, and $980 \mathrm{~mm}$, respectively. Isolation piles were fabricated using gypsum and iron wire, and the diameter was $54 \mathrm{~mm}$. The tunnel structure, diaphragm wall, and isolation piles were preburied in the soil before the foundation pit construction. The anchor cable was prepared using quick-setting cement and steel strand. The steel strand was preburied in the soil before the foundation pit excavation. The anchored section of the anchor cable was simulated by prepouring quick-setting cement in the process of filling strata materials. During the foundation pit construction, when the foundation pit was excavated below the elevation of the anchor cable,

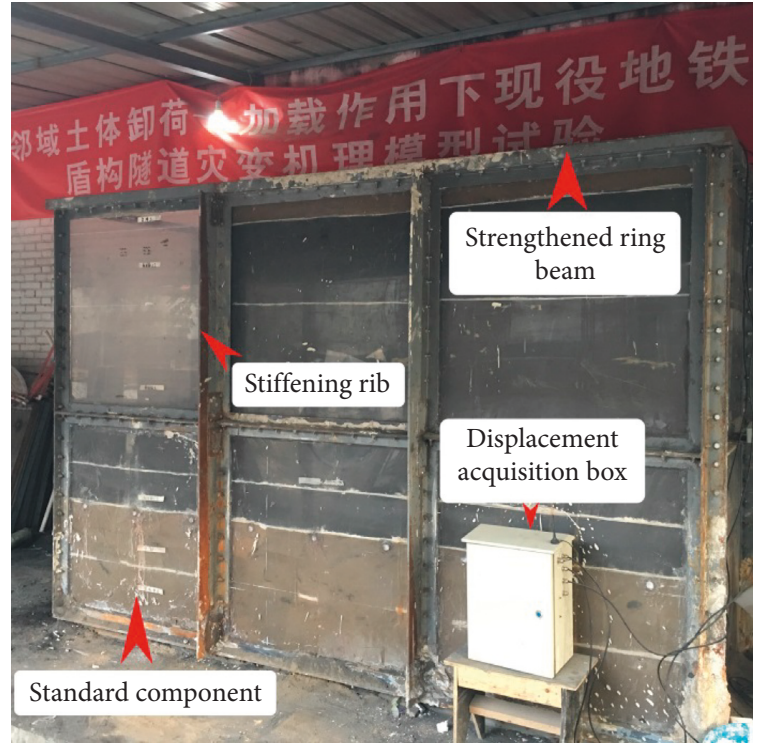

Figure 1: Model test box.

prestressing force was applied using a spring scale to stretch the steel strand, and screws were tightened when the spring scale reached the prestressing force value. Figure 2 shows the excavation of the foundation pit during the test.

During the model test, horizontal displacement of the tunnel structure was monitored, and the monitoring equipment was a guyed displacement sensor with a precision of $0.01 \mathrm{~mm}$ and a measuring range of $0-100 \mathrm{~mm}$. Displacement data were collected through the acquisition box. The displacement sensor is shown in Figure 3.

Figures 4-6 show the support structure and sensor arrangement mode in four schemes.

3.5. Construction Process in the Model Test. The model test was divided into three phases: phase I involved strata material filling and arrangement of the supporting structure, tunnel structure, and isolation piles; phase II involved 
TABLE 3: Similar material composition and matching ratio of strata.

\begin{tabular}{lccc}
\hline Stratum name & Prototype stratum thickness $(\mathrm{m})$ & Model stratum thickness $(\mathrm{cm})$ & Composition and ratio \\
\hline Miscellaneous fill & 2.0 & 13 & River sand $=1$ \\
Clayey silt I & 5.2 & 35 & River sand : iron powder : gypsum $:$ lime $=19: 8: 1: 2$ \\
Silty clay & 13.2 & 88 & River sand : iron powder $:$ gypsum $:$ lime $=19: 8: 1: 1$ \\
Clayey silt II & 1.8 & 12 & River sand : iron powder $:$ gypsum $:$ lime $=19: 8: 1: 2$ \\
Medium sand & 3.2 & 22 & River sand $=1$ \\
Pebbles & 4.5 & 30 & Iron powder $:$ river sand $=1: 20$ \\
\hline
\end{tabular}

TABLE 4: Parameters of prototype and model strata.

\begin{tabular}{|c|c|c|c|c|c|c|}
\hline \multirow{2}{*}{ Stratum name } & \multicolumn{2}{|c|}{ Cohesion $(\mathrm{kPa})$} & \multicolumn{2}{|c|}{ Internal friction angle $\left({ }^{\circ}\right)$} & \multicolumn{2}{|c|}{ Poisson's ratio } \\
\hline & Prototype stratum & Model stratum & Prototype stratum & Model stratum & Prototype stratum & Model stratum \\
\hline Miscellaneous fill & 10.00 & 0.67 & 15.00 & 1.00 & 0.36 & 0.36 \\
\hline Clayey silt I & 21.00 & 1.40 & 20.70 & 1.38 & 0.25 & 0.25 \\
\hline Silty clay & 28.70 & 1.91 & 20.60 & 1.37 & 0.26 & 0.26 \\
\hline Clayey silt II & 30.00 & 2.00 & 23.00 & 1.53 & 0.25 & 0.25 \\
\hline Medium sand & 0.00 & 0.00 & 30.00 & 2.00 & 0.27 & 0.27 \\
\hline Pebbles & 0.00 & 0.00 & 35.00 & 2.33 & 0.23 & 0.23 \\
\hline
\end{tabular}

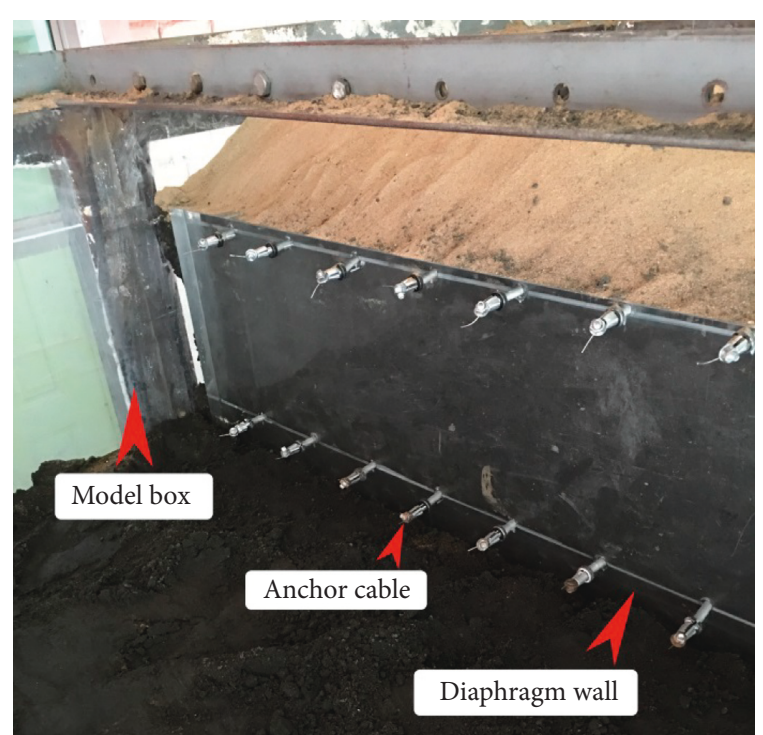

FIgURE 2: Excavation of the foundation pit during the model test.

foundation pit excavation and simulation of foundation pit excavation through stratified soil excavation. When the foundation pit was excavated below the elevation of the anchor cable, the anchor cable is tensioned; phase III involved building construction loading, during which the loading was simulated through stratified laying of cast iron weights on the foundation slab (800 mm (length) $\times 800 \mathrm{~mm}$ (width)). Given that the prototype building had 10 aboveground stories and 4 underground stories, the load of each story was $12 \mathrm{kPa}$. The weight of each cast iron was $10 \mathrm{~kg}$, and each layer was stacked with 12 weights to simulate the loading process of a two-story construction. The loading process was carried out 7 times with the load of $1.2 \mathrm{kN}$ each

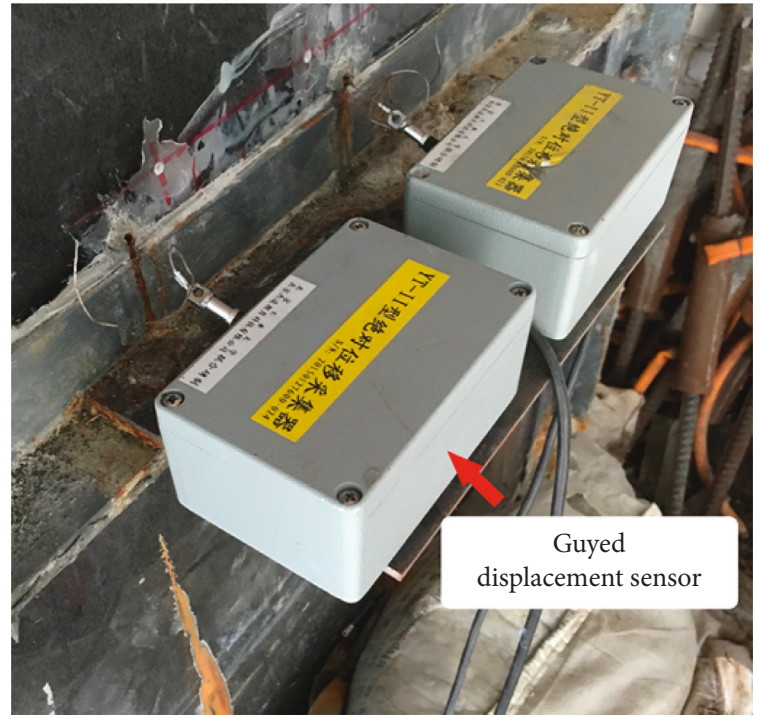

FIGURE 3: Guyed displacement sensor.

time. Table 5 shows the procedures of the model test. Figure 7 shows the diagram of procedure 20 .

3.6. Analysis of Model Test Results. Horizontal displacement data of the tunnel structure in each procedure of the model test were recorded. Positive horizontal displacement represents the movement of the tunnel structure toward the foundation pit. Figure 8 shows the model test results.

As shown in Figure 8, deformation laws of the tunnel structure in four schemes were similar. As the foundation pit excavation progressed, the soil at the rear side of the diaphragm wall experienced deformation toward the 


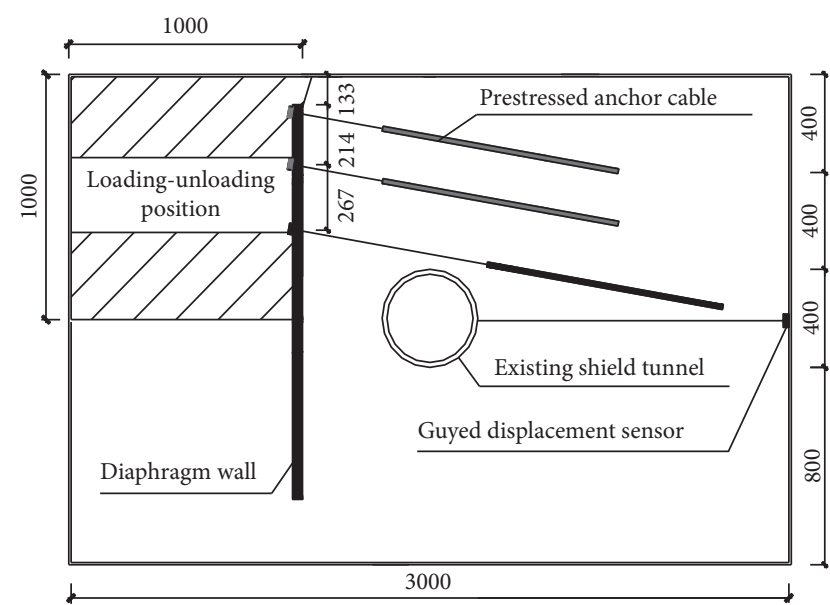

FIGURE 4: Layout of the support structure and sensor arrangement mode in scheme 0.

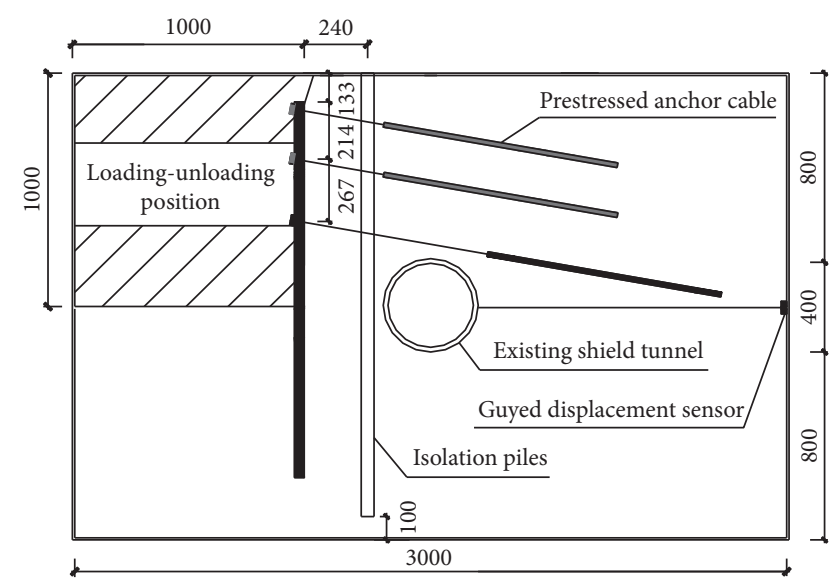

FIGURE 5: Layout of the support structure and sensor arrangement mode in scheme 1.

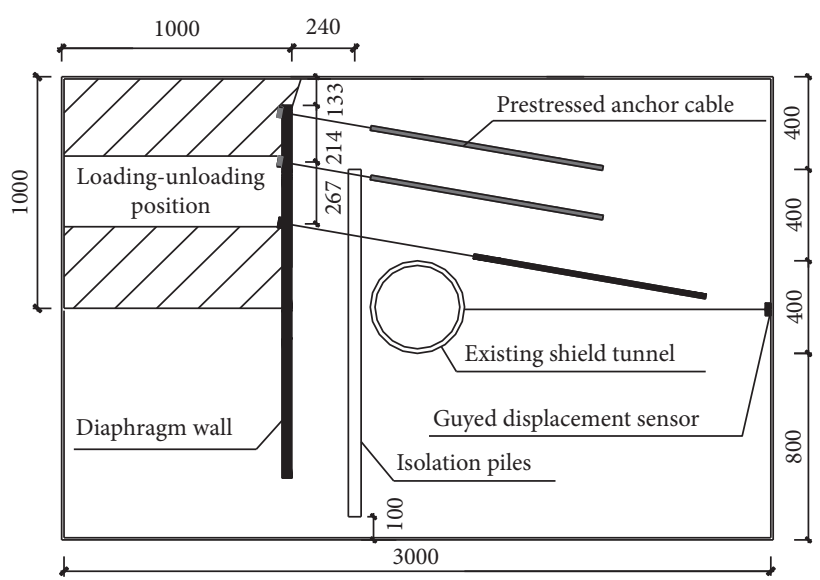

FIGURE 6: Layout of the support structure and sensor arrangement mode in schemes 2 and 3.

foundation pit under the effect of active soil pressure. The tunnel structure was extruded to generate displacement toward the foundation pit, and the displacement reached the maximum value after foundation pit excavation was
TABle 5: Procedures of the model test.

\begin{tabular}{lc}
\hline $\begin{array}{l}\text { Procedure } \\
\text { number }\end{array}$ & Procedure instructions \\
\hline 1 & Initial state (construction of the diaphragm \\
wall, isolation piles, anchor cable, and shield \\
tunnel and reading initial values) \\
Soil excavation to $-133 \mathrm{~mm}$ depth \\
3 & Construction of sloping and the first-layer \\
3 & anchor cable \\
4 & Soil excavation to $-266 \mathrm{~mm}$ depth \\
5 & Soil excavation to $-400 \mathrm{~mm}$ depth \\
6 & Construction of the second-layer anchor cable \\
7 & Soil excavation to $-533 \mathrm{~mm}$ depth \\
8 & Soil excavation to $-667 \mathrm{~mm}$ depth \\
9 & Construction of the third-layer anchor cable \\
10 & Soil excavation to $-800 \mathrm{~mm}$ depth \\
11 & Soil excavation to $-933 \mathrm{~mm}$ depth \\
12 & Soil excavation to $-1000 \mathrm{~mm}$ depth \\
13 & Waiting for $24 \mathrm{~h}$ after completion of excavation \\
14 & Loading foundation slab and weights of $1.2 \mathrm{kN}$ \\
15 & Loading weights of $2.4 \mathrm{kN}$ \\
16 & Loading weights of $3.6 \mathrm{kN}$ \\
17 & Loading weights of $4.8 \mathrm{kN}$ \\
18 & Loading weights of $6.0 \mathrm{kN}$ \\
19 & Loading weights of $7.2 \mathrm{kN}$ \\
20 & Loading weights of $8.4 \mathrm{kN}$ \\
\hline
\end{tabular}

completed. Because the model box stood still for 24 hours to simulate the intermittent time before building loading, the displacement of soil and tunnel continued to increase during the intermittent time. Therefore, the horizontal displacement of the tunnel structure continued to increase after the foundation pit excavation was completed. In the simulation of building construction loading, the tunnel structure experienced minor displacement toward outside of the foundation pit. Horizontal displacement of the tunnel structure slightly recovered. Thereafter, the tunnel structure went through displacement toward the foundation pit, but the displacement changed slightly.

Comparison of four curves in Figure 8 indicated that horizontal displacement of the tunnel structure in scheme 0 was greater than those in the other three schemes. This finding indicated that the addition of isolation piles had limiting effect on the horizontal displacement of the tunnel structure. When the burial depths of the pile top and bottom were identical in schemes 2 and 3 , the reinforcement effect under $2 D$ pile spacing was better than that under $3 D$ pile spacing. Therefore, reduction in pile spacing in practice engineering could improve the reinforcement effect of isolation piles. When the burial depth of the pile bottom and pile spacing were identical in schemes 1 and 2 , the difference in the reinforcement effect between conventional- and buried-type isolation piles was small. This result indicated that the buried depth of the pile top slightly influenced the reinforcement effect of isolation piles.

\section{Numerical Simulation Analysis}

Numerical calculation software midas GTS NX was used to simulate prototype engineering construction for further 


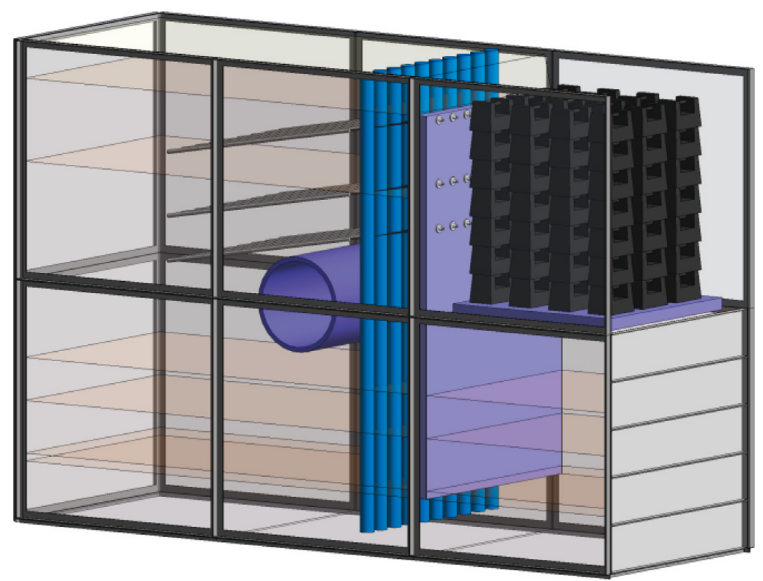

FIgURE 7: Diagram of procedure 20.

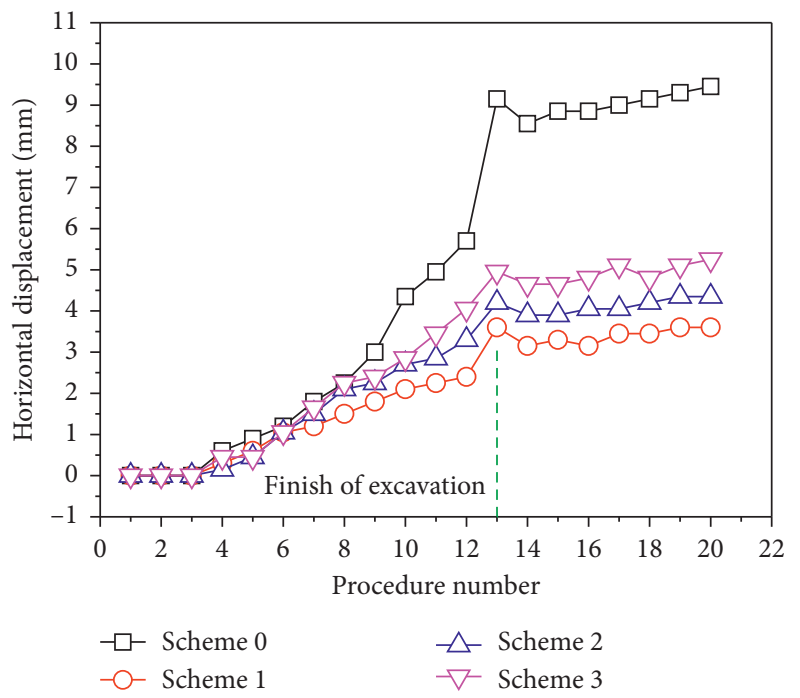

Figure 8: Horizontal displacement curve of the tunnel structure.

studying the reinforcement effect of isolation piles on the existing shield tunnel in the adjacent building construction process. The scheme of numerical calculation was the same as that of the similar material model test.

4.1. Establishment of Numerical Simulation Model. To avoid the influence of the boundary effect on the numerical simulation, the soil thickness outside the foundation pit was more than tripled foundation pit excavation depth. The length, width, and height were 90,60 , and $60 \mathrm{~m}$, respectively. Figure 9 shows the mesh of the numerical calculation model, and Figure 10 presents the mesh of isolation piles and supporting structure.

4.2. Model Parameter Values. Hardened soil model could take into account the nonlinear characteristics of stress and strain of soil and could also reflect the complex stress path of soil during excavation of the foundation pit [25]. The modified Mohr-Coulomb constitutive model in midas GTS

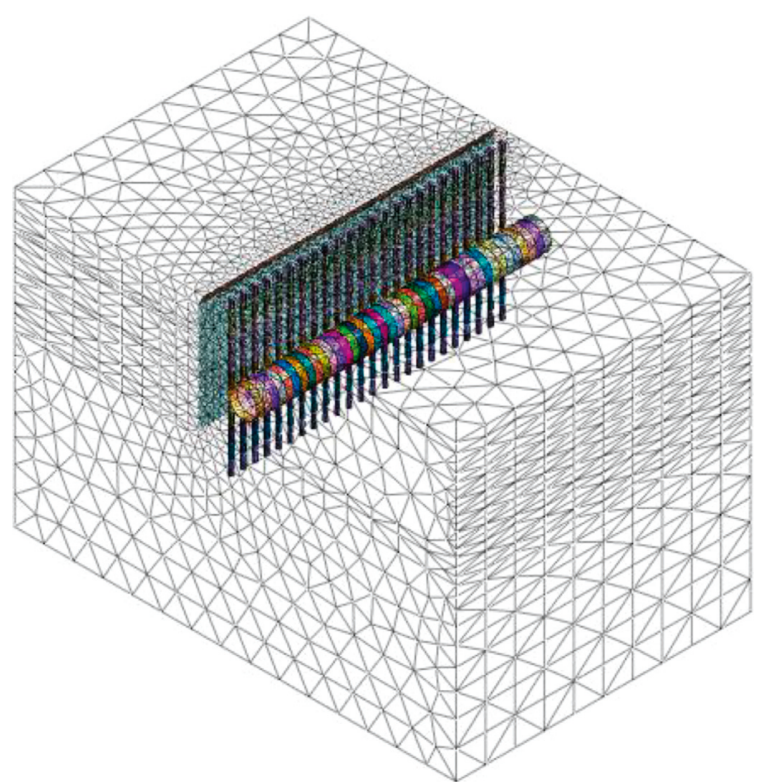

Figure 9: Mesh of the numerical calculation model.

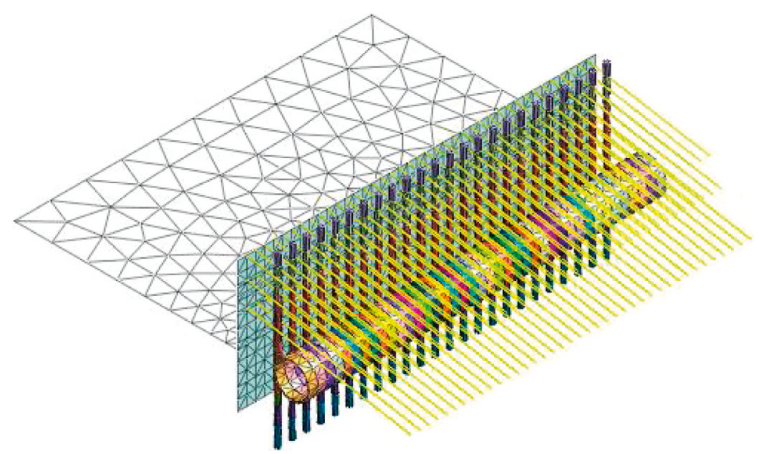

Figure 10: Mesh of isolation piles and supporting structure.

NX took into account the hardening characteristics of soil, which could better simulate the stress-strain behavior of soil during excavation of the foundation pit. Accordingly, the modified Mohr-Coulomb constitutive model was used in this study. In accordance with the suggested values of the midas GTS NX help file, unloading modulus took tripled loading modulus, and solid units were used to establish the soil. Table 1 presents the physical and mechanical parameters of the soil.

Elastic constitutive models were used for the diaphragm wall, foundation slab, anchor cable, isolation piles, and tunnel structure. The diaphragm wall, tunnel structure, and foundation slab were simulated using plate units. The isolation piles were simulated using solid units. The anchor cable was simulated using implanted-type truss units. Table 6 shows the physical and mechanical parameters of the structure.

4.3. Numerical Simulation Procedures. The procedures of numerical simulation were similar to those of the model test. The number of numerical simulation procedures was 20 (Table 7). 
TABle 6: Physical and mechanical parameters of the structure.

\begin{tabular}{lccc}
\hline Structure name & $\begin{array}{c}\text { Unit weight } \\
\left(\mathrm{kN} / \mathrm{m}^{3}\right)\end{array}$ & $\begin{array}{c}\text { Elastic modulus } \\
(\mathrm{MPa})\end{array}$ & Poisson's ratio \\
\hline Diaphragm wall & 25 & 31500 & 0.20 \\
Anchor cable & 78 & 210000 & 0.25 \\
Foundation slab & 25 & 31500 & 0.20 \\
Isolation pile & 25 & 30000 & 0.20 \\
Lining segment & 25 & 34500 & 0.20 \\
\hline
\end{tabular}

TABLE 7: Numerical simulation procedures.

\begin{tabular}{lc}
\hline $\begin{array}{c}\text { Procedure } \\
\text { number }\end{array}$ & Procedure instructions \\
\hline 1 & $\begin{array}{c}\text { Initial stress state: displacement clearing } \\
\text { Construction of the shield tunnel, isolation } \\
\text { piles, and diaphragm wall and displacement } \\
\text { clearing }\end{array}$ \\
3 & Soil excavation to $-2.0 \mathrm{~m}$ depth \\
4 & Construction of the first-layer anchor cable \\
5 & Soil excavation to $-4.0 \mathrm{~m}$ depth \\
6 & Soil excavation to $-6.0 \mathrm{~m}$ depth \\
7 & Construction of the second-layer anchor cable \\
8 & Soil excavation to $-8.0 \mathrm{~m}$ depth \\
9 & Construction of the third-layer anchor cable \\
10 & Soil excavation to $-12.0 \mathrm{~m}$ depth \\
11 & Soil excavation to $-14.0 \mathrm{~m}$ depth \\
12 & Soil excavation to $-15.0 \mathrm{~m}$ depth \\
13 & Construction of basements of -4 and -3 stories \\
14 & Construction of basements of -2 and -1 stories \\
15 & Loading of the weights for the first and second \\
16 & stories \\
17 & Loading of the weights for the third and fourth \\
18 & stories \\
& Loading of the weights for the fifth and sixth \\
& stories
\end{tabular}

\subsection{Result Analysis}

4.4.1. Horizontal Displacement Analysis of Tunnel Structure. Figure 11 shows the measuring point arrangement of the tunnel structure displacement for analyzing the tunnel structure displacement in the numerical simulation calculation results. Positive horizontal displacement represents the movement of the tunnel structure toward the foundation pit.

(1) Tunnel Structure Displacement without Isolation Pile Reinforcement. Horizontal displacement of the tunnel structure in the building construction process without isolation pile reinforcement was calculated. Figure 12 shows the results.

Figure 12 shows that, without isolation pile reinforcement, the tunnel structure experienced horizontal displacement toward the foundation pit during excavation.

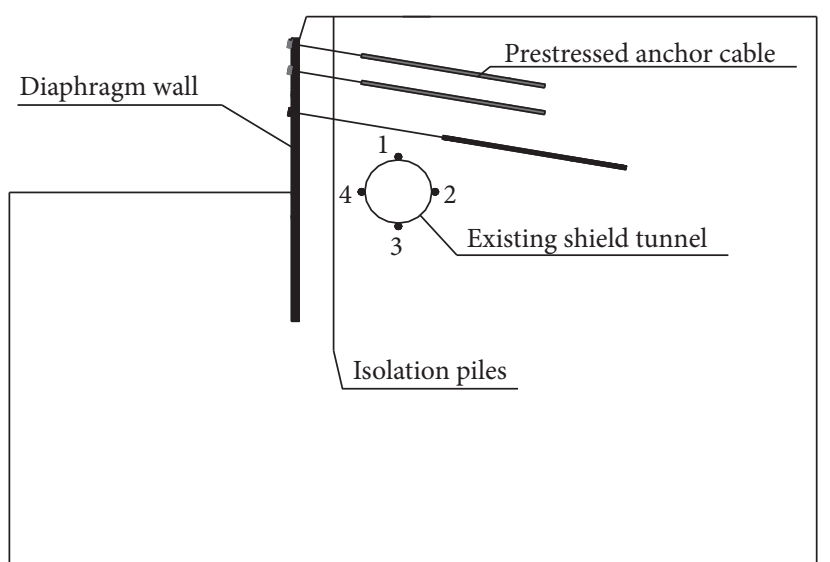

FIGURE 11: Layout of monitoring points for horizontal displacement of the tunnel structure.

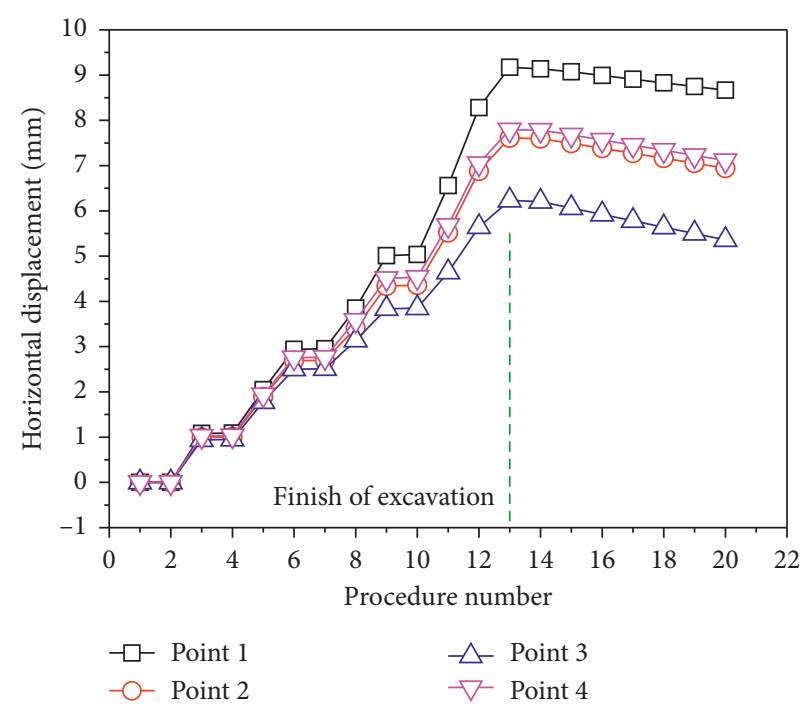

FIGURE 12: Horizontal displacement of the tunnel structure without isolation pile reinforcement.

When the foundation pit excavation was shallow, the difference in horizontal displacement between four measuring points was small. As the excavation depth increased, the horizontal deformations of the diaphragm wall and soil above the pit bottom were greater than those below the pit bottom. Consequently, the horizontal displacement at monitoring point 1 was larger than that at monitoring point 3 , and the difference gradually increased. The tunnel structure experienced torsional deformation toward the foundation pit. As the foundation pit excavation deepened, the torsional deformation became serious. After the foundation pit excavation was completed, horizontal displacement of the tunnel structure reached the maximum value. The tunnel structure roof had the maximum horizontal displacement of $9.17 \mathrm{~mm}$. The difference in displacement between the roof and the floor was $2.94 \mathrm{~mm}$.

In the building loading process, the increase in load extruded the soil at the bottom of the foundation pit. As a result, the diaphragm wall below the foundation pit bottom 
experienced deformation toward outside of the foundation pit. The tunnel structure went through minor displacement far from the foundation pit under the extruding effect of the soil. The horizontal displacement of the tunnel structure generated during the excavation unloading process recovered to a certain degree. Measuring point 3 at the bottom of the tunnel had the maximum displacement variation of $-0.87 \mathrm{~mm}$. The final difference in horizontal displacement between the tunnel structure roof and the floor was $3.31 \mathrm{~mm}$.

(2) Tunnel Structure Displacement with Isolation Pile Reinforcement. Figures 13-15 show the horizontal displacement of the tunnel structure with isolation pile reinforcement in various schemes.

As shown in Figures 13-15, displacement laws of the tunnel structure with isolation pile reinforcement were similar to those under the condition without isolation pile reinforcement. As the foundation pit excavation progressed, torsional deformation of the tunnel structure became serious. Monitoring point 1 at the tunnel structure roof had the maximum horizontal displacement, whereas monitoring point 3 at the tunnel structure floor had the minimum horizontal displacement. The difference in horizontal displacement between monitoring points 4 and 2 of the tunnel structure was small, and the tunnel structure did not experience horizontal expansion deformation. As the building loading progressed, horizontal displacement of the tunnel structure slightly recovered.

The tunnel structure displacement laws in numerical simulation were generally similar to those in the model test. The curve inflection point appeared after excavation of the foundation pit, and the calculation model was reasonable.

In the building loading stage, the horizontal displacement of the tunnel structure increased slightly in the model test. The reason was that the building loading process in the model test was simulated by stratified laying of cast iron weights at the bottom of the foundation pit. Given the existence of gap between cast iron weights and the diaphragm wall, the diaphragm wall above the excavation surface and the neighboring soil would slightly move toward the foundation pit during the subsequent loading process. Under the comprehensive influence, the tunnel structure also produced slight displacement toward the foundation pit, but the displacement increment was slight. The horizontal displacement laws of the tunnel structure obtained by the two research methods were approximately identical, and the total displacement had little difference. The backfilling of the gap between the building and the diaphragm wall in numerical simulation restricted the horizontal displacement of the diaphragm wall toward the foundation pit, which agreed well with engineering practice.

Figure 12 shows that horizontal displacement at monitoring point 2 was slightly smaller than that at monitoring point 4 , and the tunnel structure experienced outward expansion deformation in the horizontal direction. As shown in Figures 13-15, horizontal displacement at monitoring point 2 overlapped with that at measuring point 4 . Therefore, the difference in horizontal displacement between the left

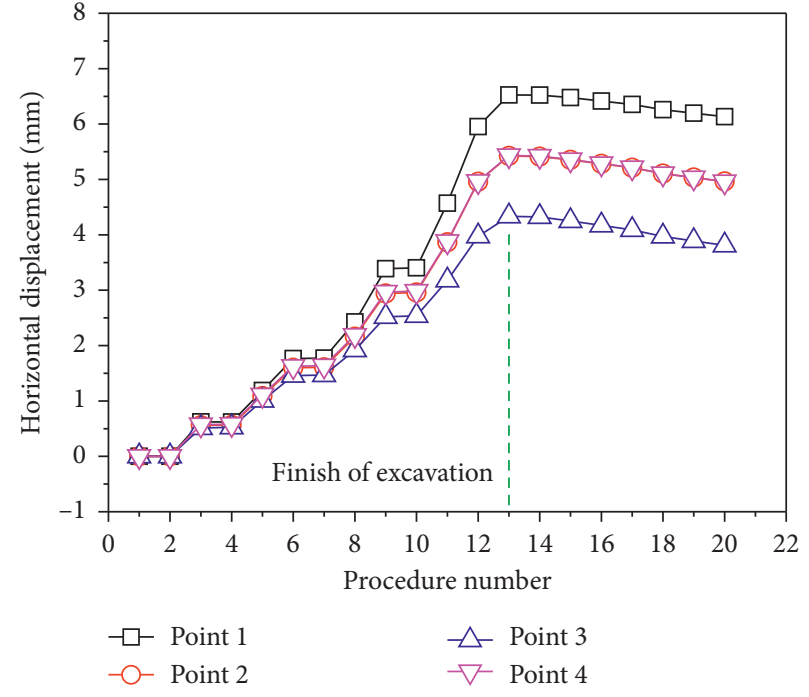

Figure 13: Horizontal displacement of the tunnel structure in scheme 1 .

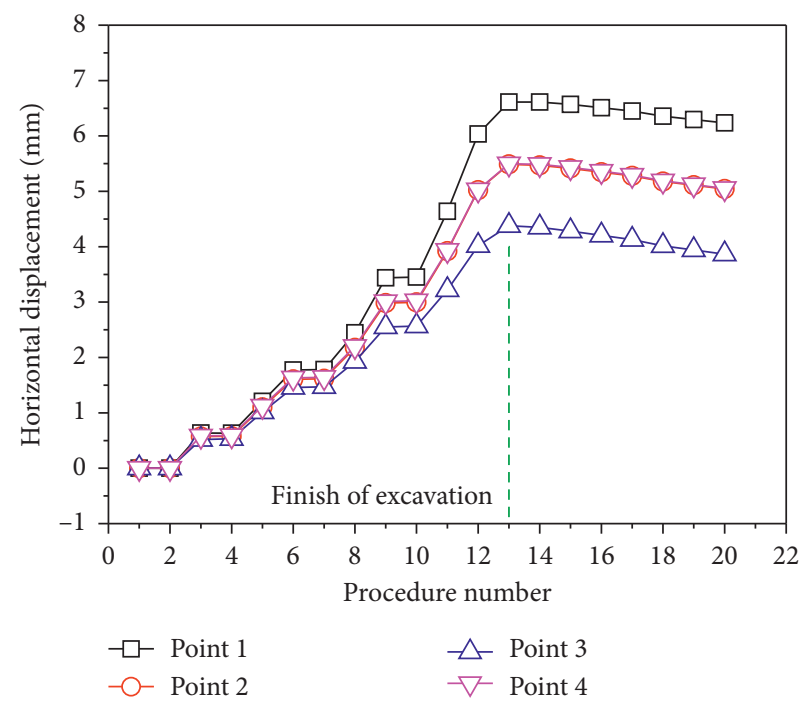

FIgURE 14: Horizontal displacement of the tunnel structure in scheme 2 .

and right sides of the tunnel structure could be decreased, and the horizontal expansion deformation of the tunnel structure could be decreased by isolation pile reinforcement. Table 8 shows the tunnel structure deformation values.

As shown in Table 8, the building loading process would increase the horizontal displacement difference between the tunnel structure roof and the floor. As a result, the torsional deformation degree of the tunnel structure further elevated. During building construction in the engineering practice, tunnel structure monitoring should be enhanced and shear failure of the tunnel structure and connecting bolt caused by large torsional deformation of the tunnel structure should be prevented. Compared with the condition without isolation pile reinforcement, maximum horizontal displacement of the tunnel structure and differences in horizontal displacement 


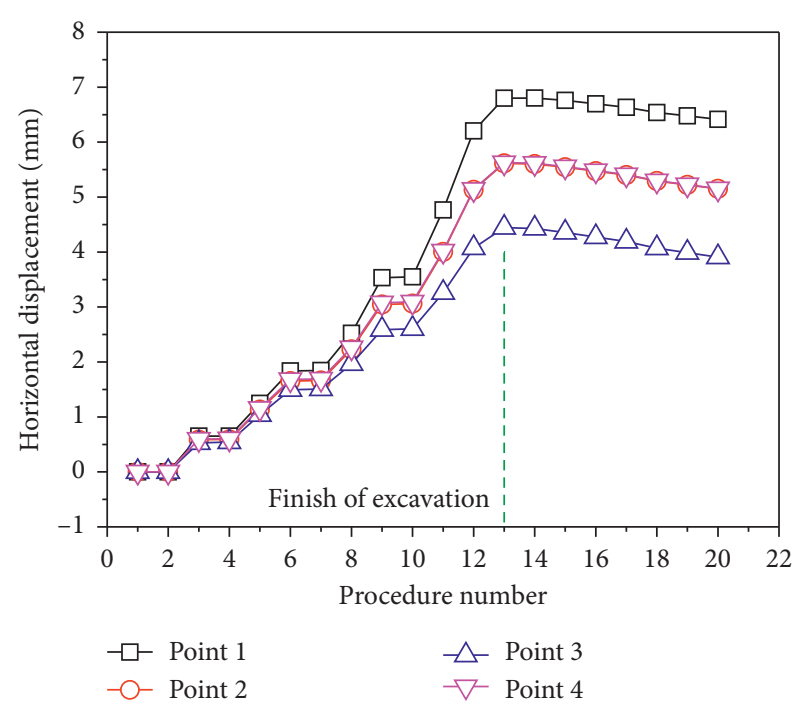

FIGURE 15: Horizontal displacement of the tunnel structure in scheme 3 .

TABle 8: Deformation values of the tunnel structure.

\begin{tabular}{lccc}
\hline $\begin{array}{l}\text { Scheme } \\
\text { number }\end{array}$ & $\begin{array}{c}\text { Maximum } \\
\text { horizontal } \\
\text { displacement } \\
(\mathrm{mm})\end{array}$ & $\begin{array}{c}W \text { after } \\
\text { foundation } \\
\text { pit excavation } \\
(\mathrm{mm})\end{array}$ & $\begin{array}{c}W \text { after } \\
\text { building } \\
\text { loading }(\mathrm{mm})\end{array}$ \\
\hline 0 & 9.17 & 2.94 & 3.31 \\
1 & 6.53 & 2.19 & 2.32 \\
2 & 6.61 & 2.23 & 2.38 \\
3 & 6.80 & 2.36 & 2.50 \\
\hline
\end{tabular}

$W$ is the horizontal displacement difference between the tunnel structure roof and the floor.

between the tunnel structure roof and the floor were decreased under the condition with isolation pile reinforcement. Isolation pile reinforcement could reduce horizontal displacement and torsional deformation of the existing tunnel structure. Comparison of the deformation values of the tunnel structure in schemes 1 and 2 showed that the increase in burial depth of the pile top inconsiderably influenced the reinforcement effect of isolation piles. The reason was that isolation piles reduced deformations of the tunnel structure through joint stress bearing of the part embedded below the displacement-affected area of pit excavation and the part within a certain range above the existing tunnel axis elevation. Comparison of schemes 2 and 3 indicated that, after spacing of isolation piles was increased, horizontal displacement of the tunnel structure and differences in horizontal displacement between the structure roof and the floor slightly increased. Consequently, the tunnel structure torsion slightly increased. The increase in pile spacing would reduce the reinforcement effect of isolation piles. Thus, proper pile spacing should be selected in the layout plan of isolation piles.

4.4.2. The Internal Force Analysis of Transverse Tunnel Structure. Eight locations on the tunnel structure are selected as monitoring points. The additional internal force of the transverse tunnel structure indicates internal force in any procedure minus initial internal force. Figure 16 shows the internal force monitoring points of the transverse tunnel structure, and the angle between each measuring point is $45^{\circ}$. The positive value of normal force indicates that the section is stretched. The positive value of bending moment implies that the inside of the tunnel structure is stretched and the outside of the tunnel structure is compressed. The positive value of shear force suggests that the microsection of the tunnel structure turns clockwise.

(1) Analysis of Additional Axis Force. Figure 17 shows the normal force of the tunnel structure in scheme 0 . The additional normal forces of the tunnel structure after the foundation pit excavation and building loading in schemes $0,1,2$, and 3 are shown in Figures 18 and 19.

As shown in Figure 17, the normal force at monitoring points $5,7,9$, and 11 had a slight difference after the foundation pit excavation. The normal force at monitoring points 6 and 10 decreased, whereas those at monitoring point 8 and 12 increased. A slight difference in the normal force of the tunnel structure was observed after the building loading and foundation pit excavation.

Figure 18 shows that the additional normal forces of the tunnel structure at monitoring points 6,9 , and 12 in the four schemes were insignificantly different when the excavation of the foundation pit was completed. Moreover, the reinforcement effect of isolation piles was not obvious. At monitoring points 8 and 11 , the additional normal force under the condition of isolation pile reinforcement was large, and the reinforcement effect of isolation piles could reduce the increase in tunnel structure normal force. At monitoring points 5 and 10 , the additional normal forces in schemes $0,1,2$, and 3 were positive. This condition indicated that the normal forces of the tunnel structure are decreasing.

At monitoring point 7 , the additional normal force of the tunnel with the isolation pile reinforcement was large and positive. This condition showed that the reinforcement effect of isolation piles could reduce the normal force of the tunnel structure.

A slight difference in the additional normal forces of the tunnel structure was observed in schemes 1, 2, and 3. Under the condition of isolation pile reinforcement, the additional normal force of the tunnel structure at monitoring point 11 was approximately $23.2 \mathrm{kPa}$ larger than that without isolation pile reinforcement, and the reinforcement effect was the most evident.

Analysis of Figure 19 shows that the additional normal forces of the tunnel structure at monitoring points 5, 6, and 10 slightly differed under the conditions with isolation pile reinforcement and without isolation pile reinforcement after the building loading. At monitoring points 8, 11, and 12, the additional normal forces of the tunnel structure under the condition of isolation pile reinforcement were large, and the reinforcement effect was evident. At monitoring points 7 and 9 , the reinforcement effect of isolation piles could reduce the normal forces. The additional normal forces at monitoring points in schemes 1,2 , and 3 were close, and the 


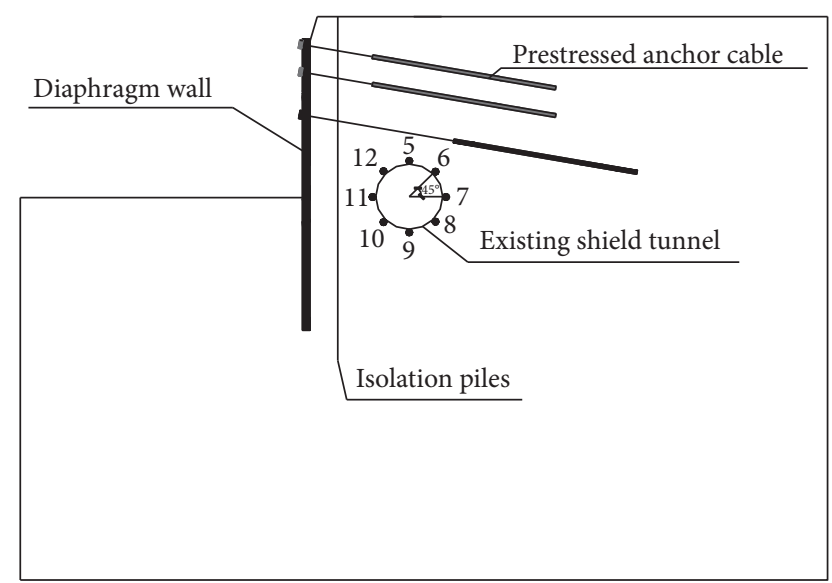

FIGURE 16: Layout of monitoring points for internal forces of the transverse tunnel structure.

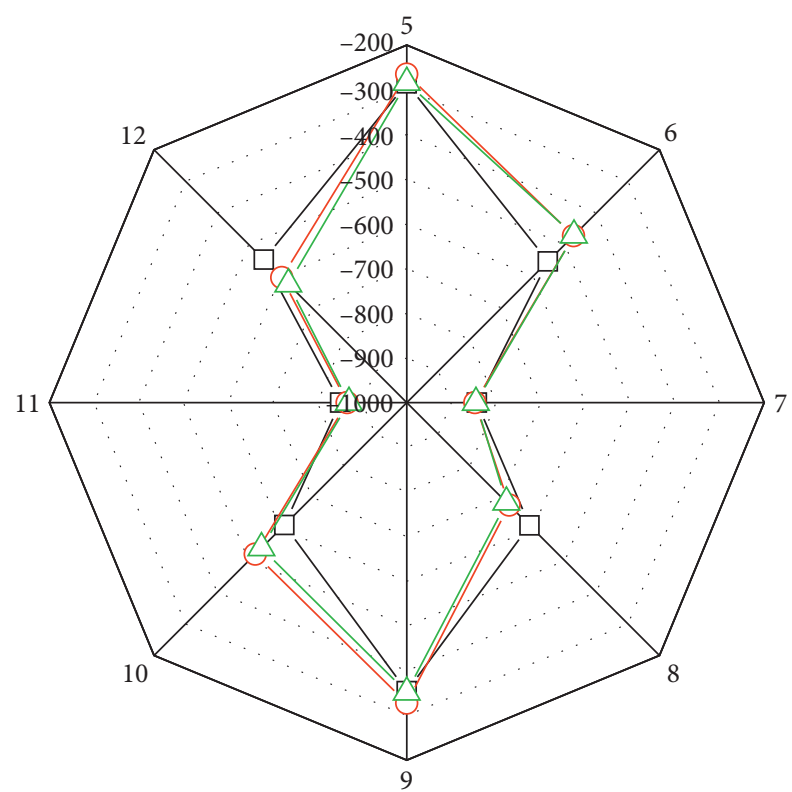

Unit: kN

$-\square$ - Initial

- $\bigcirc$ - After excavation

$-\triangle$ - After loading

FIGURE 17: Normal forces of the tunnel structure in scheme 0 .

reinforcement effects were similar. At monitoring point 11, the maximum difference between additional normal forces with and without isolation pile reinforcement was nearly $25.92 \mathrm{kPa}$, and the reinforcement effect was the most evident.

(2) Analysis of Additional Bending Moment. Figure 20 shows the bending moments of the tunnel structure in scheme 0 . The additional bending moments of the tunnel structure after the foundation pit excavation and building loading in schemes $0,1,2$, and 3 are shown in Figures 21 and 22.

Figure 20 shows no evident difference in bending moments at monitoring points $5,7,9$, and 11 after foundation pit excavation, and the bending moment at monitoring

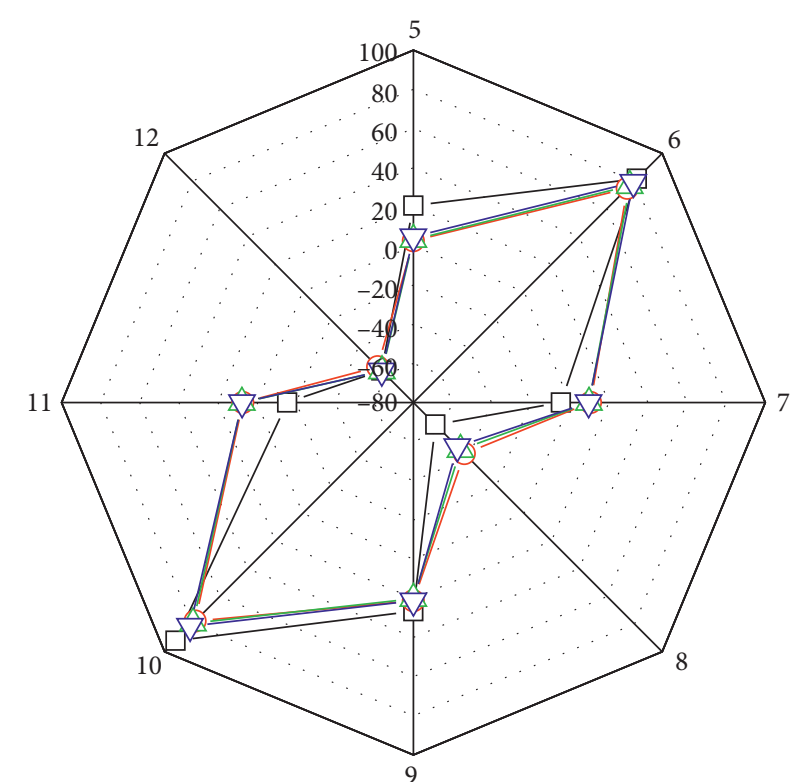

Unit: kN

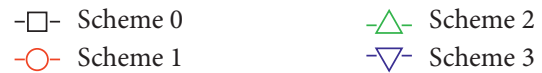

Figure 18: Additional normal forces of the tunnel structure after the foundation pit excavation.

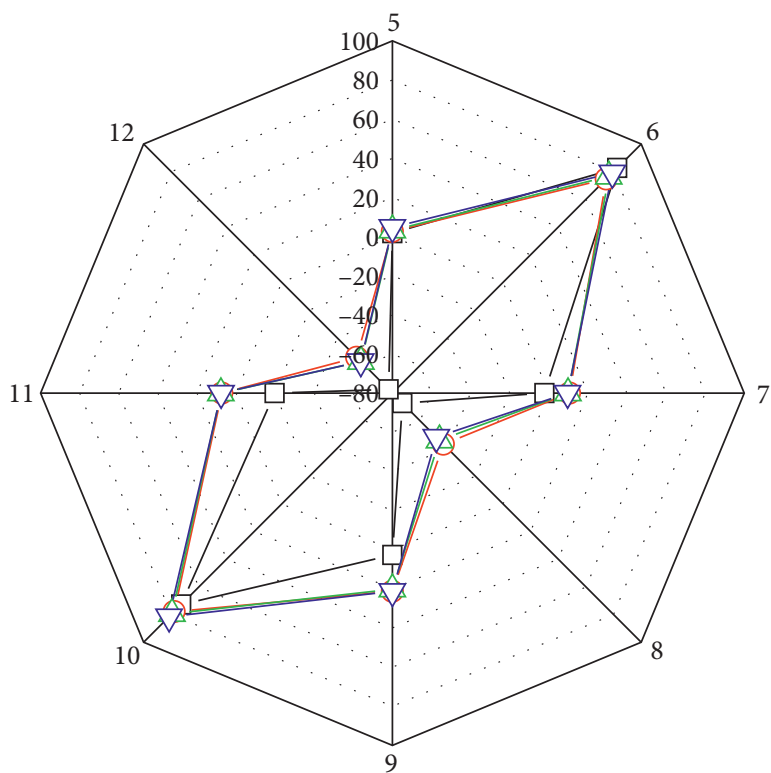

Unit: $\mathrm{kN}$

$$
\begin{array}{ll}
-\square \text { - Scheme 0 } & -\triangle \text { - Scheme 2 } \\
-\bigcirc-\text { Scheme 1 } & -\nabla \text { - Scheme 3 }
\end{array}
$$

FIGURE 19: Additional normal forces of the tunnel structure after the building loading.

points $6,8,10$, and 12 increased. The bending moments had no evident difference after the foundation pit excavation and building loading.

Comparing Figures 20 and 21 indicates that the bending moments of the tunnel structure in scheme 0 increased after 


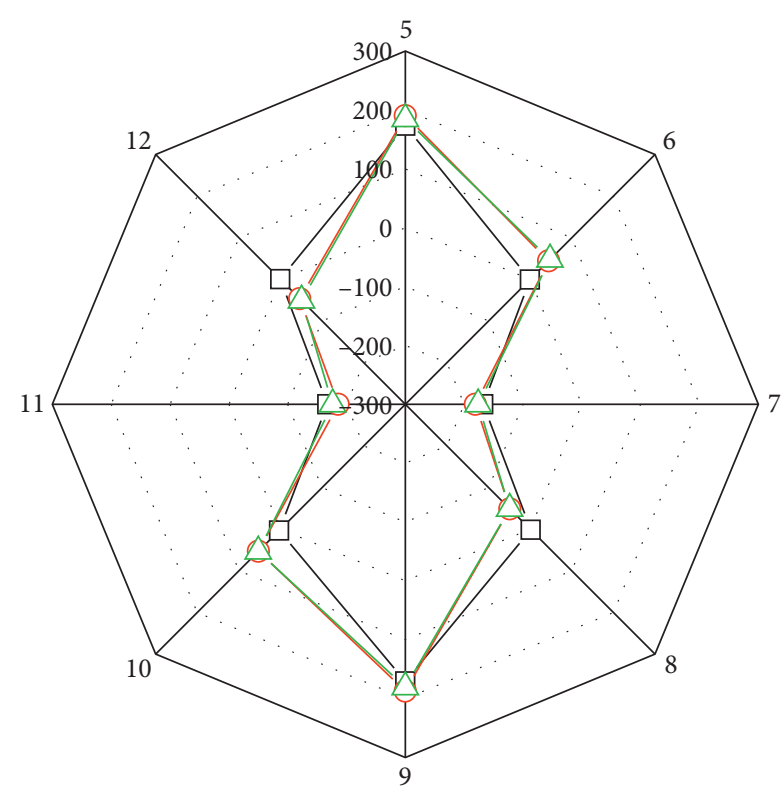

Unit: $\mathrm{kN} \cdot \mathrm{m}$

$-\square$ - Initial

- - - After excavation

$-\triangle$ - After loading

FIGURE 20: Bending moments of the transverse tunnel structure in scheme 0 .

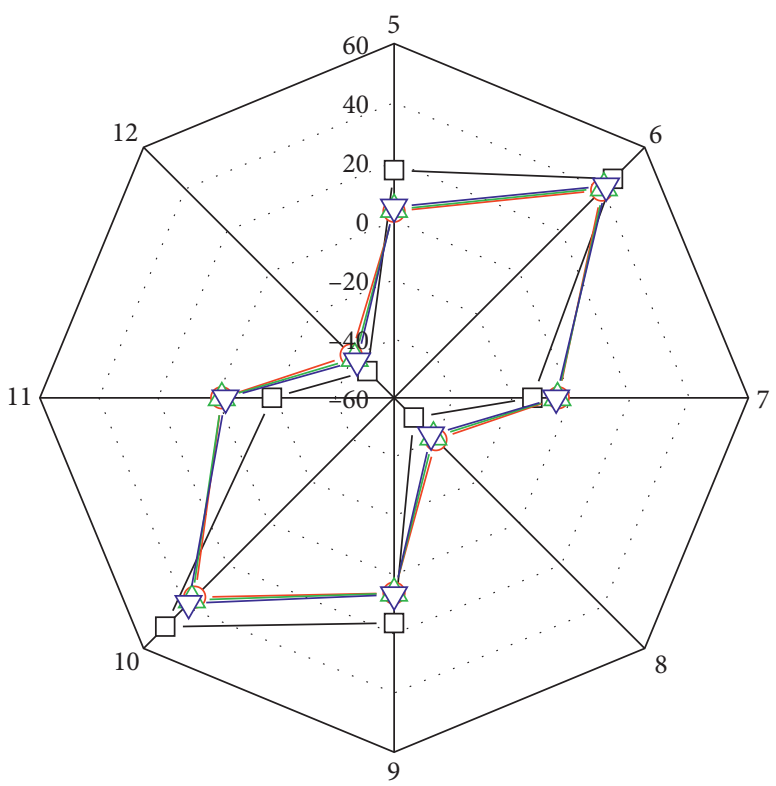

Unit: $\mathrm{kN} \cdot \mathrm{m}$

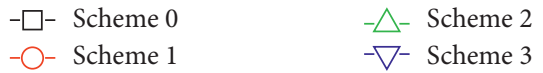

FIgURE 21: Additional bending moments of the tunnel structure after the foundation pit excavation.

foundation pit excavation. However, under the condition of isolation pile reinforcement, the increase in bending moments at different locations of the tunnel structure was small. The existence of isolation piles inhibited the increasing trend

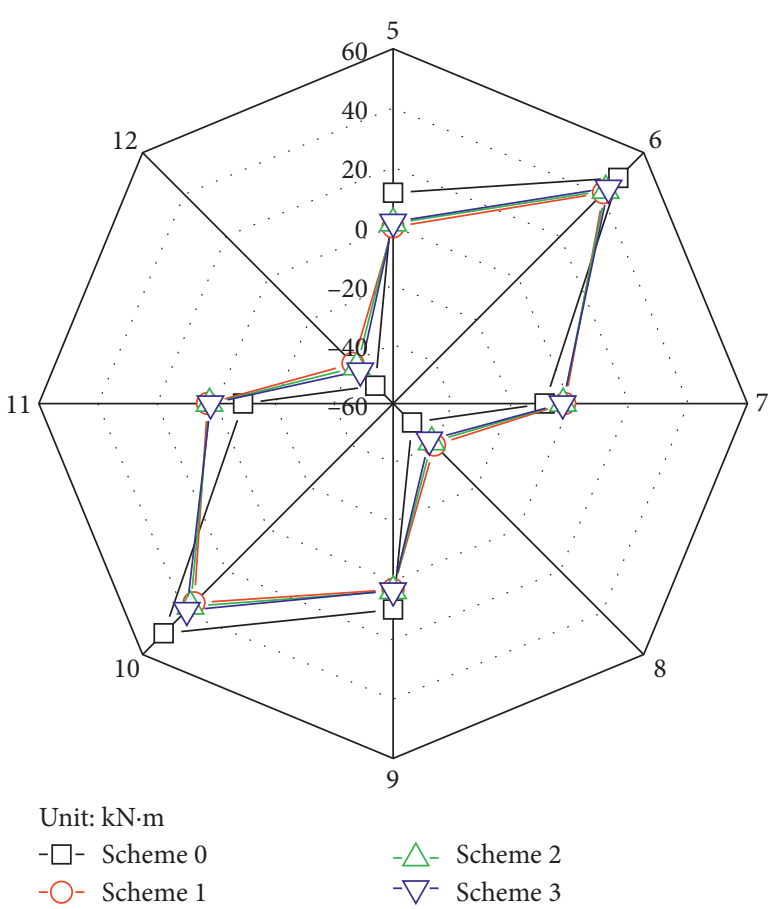

Figure 22: Additional bending moments of the tunnel structure after the building loading.

of the bending moments, and the reinforcement effect was evident.

At monitoring point 11 , the maximum difference between the additional bending moments with and without isolation pile reinforcement was approximately $17 \mathrm{kNm}$, and the reinforcement effect was the most evident.

Similar rules were obtained when comparing Figures 21 and 22. The reinforcement effect of isolation piles could reduce the increasing trend of bending moments after the building loading. At monitoring point 10, the difference between the additional bending moments with and without isolation piles was the largest, and the maximum difference of additional bending moments was $-14.57 \mathrm{kN} \cdot \mathrm{m}$.

(3) Analysis of Additional Shear Force. Figure 23 shows the shear forces of the tunnel structure in scheme 0 . The additional shear forces of the tunnel structure after foundation pit excavation and building loading in schemes $0,1,2$, and 3 are shown in Figures 24 and 25.

As shown in Figure 23, the shear forces increased at different monitoring points after foundation pit excavation. After foundation pit excavation and building loading, the change in shear forces of the tunnel structure was not evident.

Analysis of Figures 23-25 shows that the reinforcement effect of isolation piles could reduce the increasing trend of shear forces after foundation pit excavation and building loading. At monitoring point 12, the difference between the additional shear forces with and without isolation pile reinforcement was the largest at approximately $-8.93 \mathrm{kN}$ after foundation pit excavation and $-7.34 \mathrm{kN}$ after building load. 


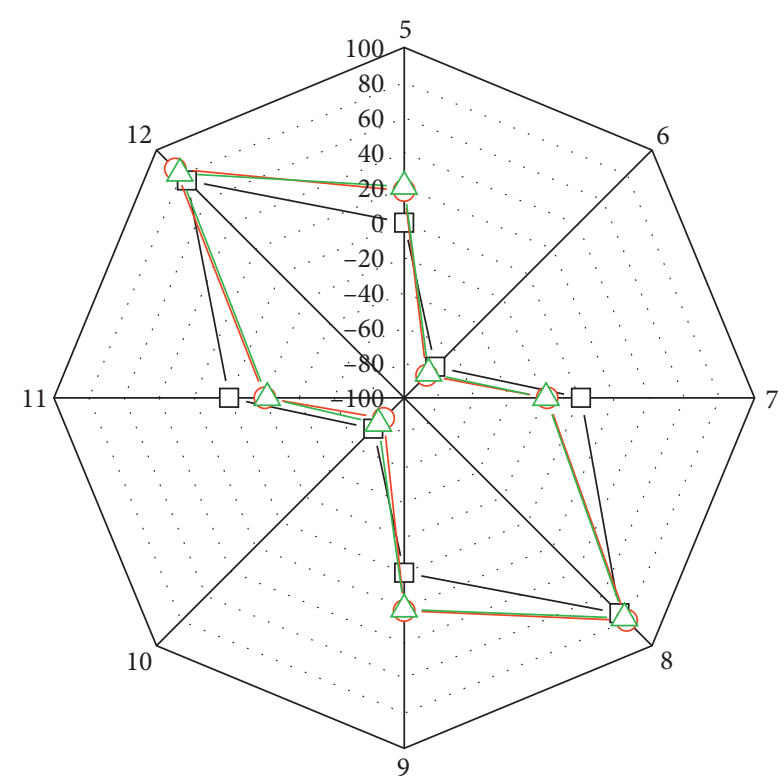

Unit: $\mathrm{kN}$

$-\square$ - Initial

- $\bigcirc-$ After excavation

$-\triangle$ - After loading

Figure 23: Shear forces of the tunnel structure in scheme 0.

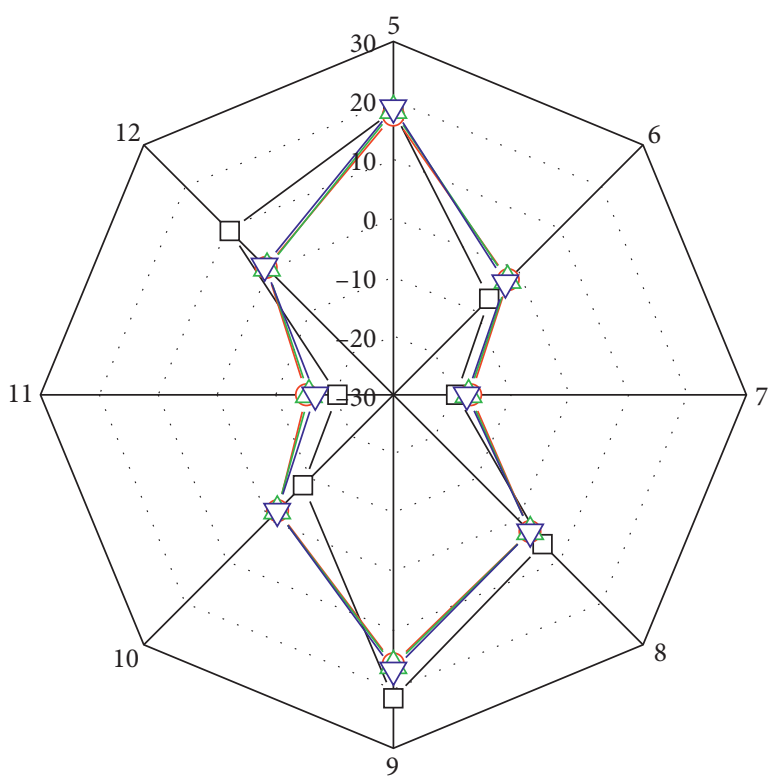

Unit: $\mathrm{kN}$

$$
\begin{array}{ll}
-\square \text { - Scheme 0 } & -\triangle \text { - Scheme 2 } \\
-\bigcirc \text { - Scheme 1 } & -\nabla \text { - Scheme 3 }
\end{array}
$$

Figure 24: Additional shear forces of the tunnel structure after foundation pit excavation.

The above-mentioned analysis revealed that the internal forces of the transverse tunnel structure increased generally after foundation pit excavation and building loading because of the extruding effect of the soil. The existence of isolation piles could play the role of bearing horizontal load of soil,

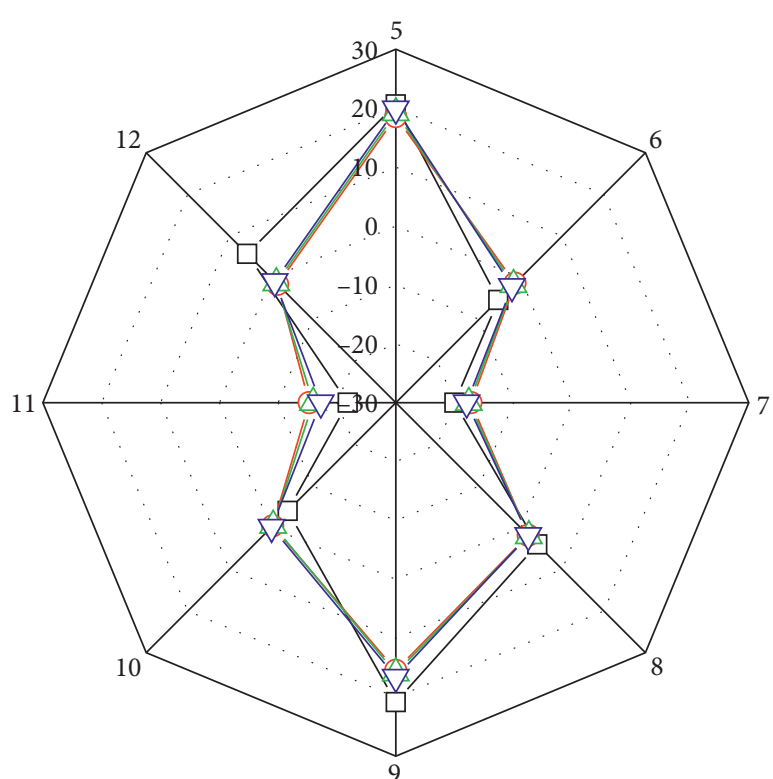

Unit: kN

$$
\begin{array}{ll}
-\square \text { - Scheme 0 } & -\triangle \text { - Scheme 2 } \\
-\bigcirc-\text { Scheme 1 } & -\nabla \text { - Scheme 3 }
\end{array}
$$

FIGURE 25: Additional shear forces of the tunnel structure after building loading.

reduce the horizontal displacement of the soil, and weaken the extruding effect of the soil on the tunnel structure. The increases in internal forces of the transverse tunnel structure were restrained to varying degrees.

\section{Influencing Factors of Reinforcement Effects of Isolation Piles}

The decrement in maximum horizontal displacement was used to evaluate the reinforcement effect of isolation piles on horizontal displacement of the tunnel structure, and the reduction rate of the horizontal displacement difference between the tunnel structure roof and the floor was used to evaluate the reinforcement effect of isolation piles on torsional deformation of the tunnel structure. The decrement in maximum horizontal displacement at monitoring point 1 of the tunnel structure with isolation pile reinforcement was defined as $\Delta S$, as shown in equation (1). The reduction rate of the horizontal displacement difference between the tunnel structure roof and the floor was defined as $\beta$, as shown in equation (2):

$$
\begin{aligned}
\Delta S & =S_{0}-S_{Z}, \\
\beta & =\frac{W_{0}-W_{Z}}{W_{0}} \times 100 \%,
\end{aligned}
$$

where $S_{0}$ is the maximum horizontal displacement at monitoring point 1 of the tunnel structure without isolation pile reinforcement, $S_{Z}$ is the maximum horizontal displacement at monitoring point 1 of the tunnel structure with isolation pile reinforcement, $W_{0}$ is the horizontal displacement 
difference between the tunnel structure roof and the floor under the condition without isolation pile reinforcement, and $W_{Z}$ is the horizontal displacement difference between the tunnel structure roof and the floor under the condition with isolation pile reinforcement.

The following equations were used to evaluate the restraint effect of isolation piles on the increase of internal forces of the transverse tunnel structure:

$$
\begin{gathered}
\Delta N=N_{Z}-N_{0}, \\
\Delta Q=Q_{Z}-Q_{0}, \\
\Delta M=M_{Z}-M_{0},
\end{gathered}
$$

where $N_{Z}$ and $N_{0}$ are the additional internal forces of the tunnel structure with and without isolation pile reinforcement, respectively; $Q_{Z}$ and $Q_{0}$ are the additional shear forces of the tunnel structure with and without isolation pile reinforcement, respectively; and $M_{Z}$ and $M_{0}$ are the additional bending moments of the tunnel structure with and without isolation pile reinforcement, respectively.

The monitoring points with the greatest effect of internal force reinforcement on the transverse tunnel structure under the condition of isolation pile reinforcement are selected for analysis. After the foundation pit excavation, the bending moment and normal force of the tunnel structure at monitoring point 11 and the shear force of the tunnel structure at monitoring point 12 are selected for analysis. After the building loading, the normal force of the tunnel structure at monitoring point 11 , the bending moment of the tunnel structure at monitoring point 10 , and the shear force of the tunnel structure at monitoring point 12 are selected for analysis.

\subsection{Influence of Burial Depth of the Isolation Pile Top on Reinforcement Effects}

5.1.1. Analysis of Control Effects on Tunnel Structure Displacement. The initial burial depth of the pile top was $0.5 Z$, and the increment was $0.125 Z$. The burial depth of the pile top was divided into $0.5 Z, 0.625 Z, 0.75 Z, 0.875 Z, 1 Z$, and $1.125 Z$. The pile spacing, pile diameter, and burial depth of the pile bottom were $3 D, 0.8 \mathrm{~m}$, and $2 H$, respectively. The calculation was carried out in six groups of numerical simulation tests, where $H$ is the excavation depth of the foundation pit, $Z$ is the burial depth of the tunnel axis, and $D$ is the diameter of the isolation pile. Figure 26 shows the calculation results. Table 9 shows the reinforcement effect of isolation piles on torsional deformation of the tunnel structure.

Figure 26 shows that when the elevation of the isolation pile top was above the tunnel structure roof, the reinforcement effect changed slightly as the burial depth of the isolation pile top increased. When the pile top was located below the tunnel structure roof, the reinforcement effect decreased. This result indicated that when elevation of the pile top was below the tunnel structure roof, the limiting effect of isolation piles on displacement of the soil around

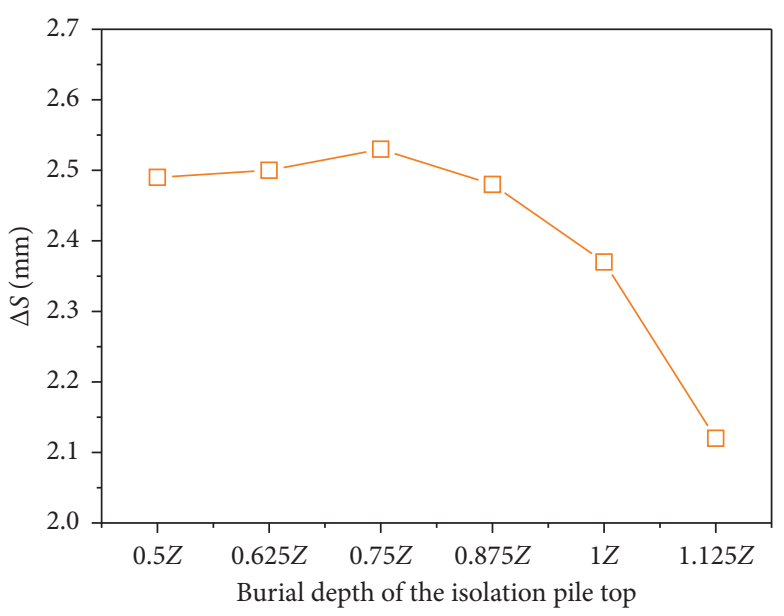

FIGURE 26: Decrement in maximum horizontal displacement of the tunnel structure under different isolation pile top depths.

TABLE 9: Reinforcement effects of isolation piles on torsional deformation of the tunnel structure under different isolation pile top depths.

\begin{tabular}{lcc}
\hline Isolation pile top depth & $\begin{array}{c}\beta \text { after foundation pit } \\
\text { excavation (\%) }\end{array}$ & $\begin{array}{c}\beta \text { after building } \\
\text { loading (\%) }\end{array}$ \\
\hline $0.5 Z$ & 21.26 & 25.76 \\
$0.625 Z$ & 21.63 & 26.74 \\
$0.75 Z$ & 21.25 & 25.30 \\
$0.875 Z$ & 15.99 & 19.88 \\
$1 Z$ & 10.39 & 14.14 \\
$1.125 Z$ & 2.64 & 6.42 \\
\hline
\end{tabular}

the tunnel structure weakened and horizontal deformation of the soil and the tunnel structure relatively increased.

Analysis of Table 9 shows that when the isolation pile top was located below the tunnel structure roof, the reinforcement effect of isolation piles on torsional deformation of the tunnel structure weakened as burial depth increased. When the burial depth was $1.125 Z$, the reduction rates $\beta$ after foundation pit excavation and building loading were $2.64 \%$ and $6.42 \%$, respectively. The reinforcement effect on torsional deformation of the tunnel structure could also be neglected. When isolation pile top elevation was above the tunnel structure roof, the increase in burial depth of the pile top slightly influenced the reinforcement effect on torsional deformation of the tunnel structure. In the layout plan of isolation piles in the engineering practice, burial depth of the pile top should be reasonably set to ensure safety and economic efficiency of the layout plan.

5.1.2. Analysis of Control Effects on Internal Force of Transverse Tunnel Structure. The difference between the additional normal forces is shown in Figure 27, the difference between the additional bending moments is shown in Figure 28, and the difference between the additional shear forces is shown in Figure 29.

Figures 18 and 19 show that the additional normal force at monitoring point 11 in scheme 0 was negative, and the 


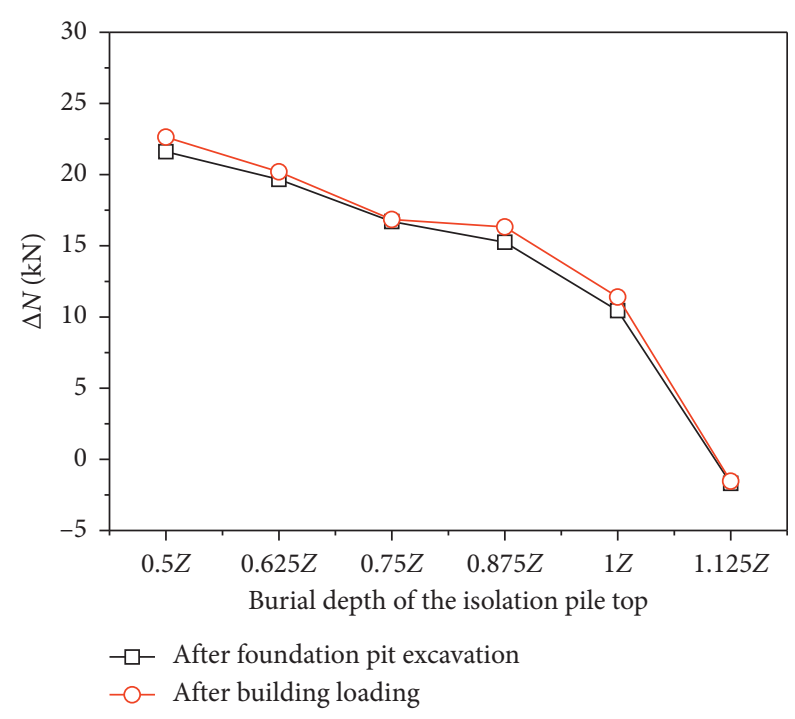

Figure 27: Difference between the additional normal forces.

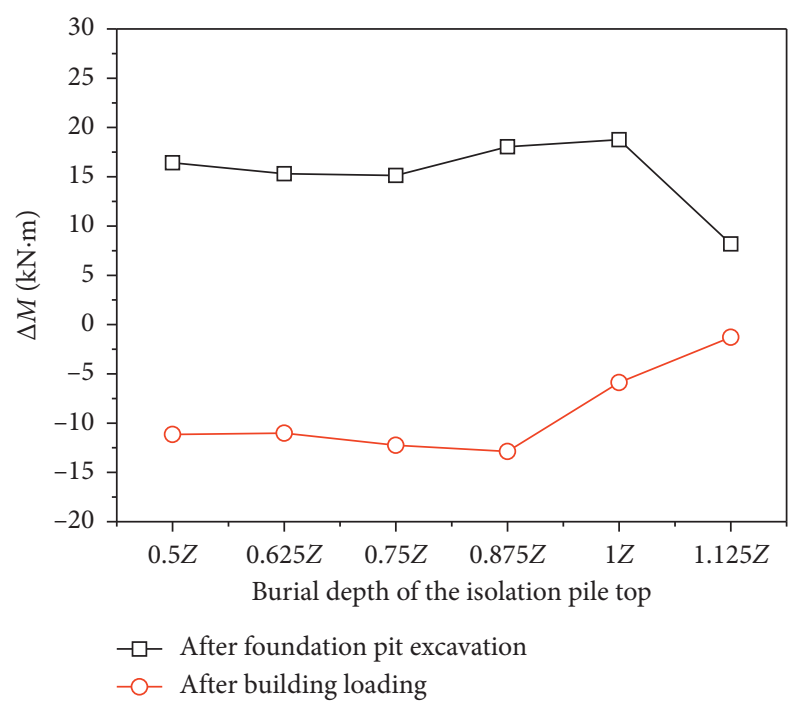

FIgURE 28: Difference between the additional bending moments.

construction process increased the normal force of the tunnel structure. Therefore, a large $\Delta N$ under the condition of isolation pile reinforcement corresponded to a small increase in tunnel structure normal force and an improved reinforcement effect. As shown in Figure 27, $\Delta N$ decreased with the increase in the buried depth of the isolation pile top after foundation pit excavation and building loading, and the restraint effect of isolation piles on the increasing trend in normal force of the tunnel structure decreased gradually.

Analysis of Figures 21 and 22 showed that the additional bending moment at monitoring point 10 in scheme 0 was positive, whereas the additional bending moment at monitoring point 11 was negative. These results combined with the initial bending moments of the transverse tunnel structure indicated that the bending moment increased after the foundation pit excavation and building loading.

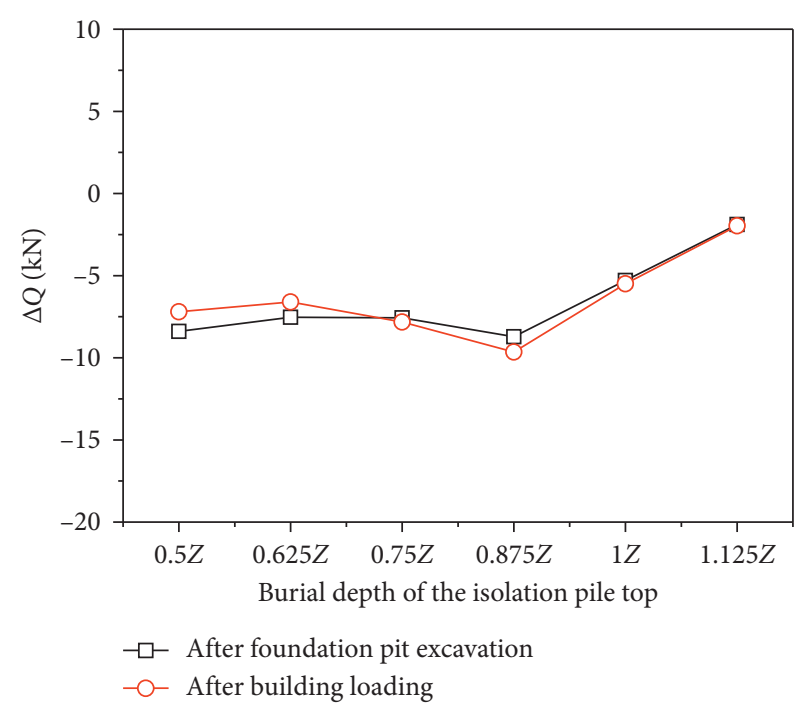

FIGURE 29: Difference between the additional shear forces.

Therefore, a small $\Delta M$ at monitoring point 10 under the condition of isolation pile reinforcement indicates an improved restraint effect. Furthermore, a large $\Delta M$ at monitoring point 11 under the above-mentioned condition corresponds to an improved restraint effect.

Analysis of Figure 28 shows that, after the foundation pit excavation and the building loading, if the elevation of the isolation pile top was above the tunnel structure roof, the restraint effects of isolation piles on the increasing trend in bending moment of the tunnel structure were similar, and if it was below the tunnel structure roof, the restraint effects of isolation piles decreased evidently.

Figures 24 and 25 show that the additional shear force of the tunnel structure at monitoring point 12 under the condition without isolation pile reinforcement was positive. The shear force of the tunnel structure increased after foundation pit excavation and building loading. Thus, a small $\Delta Q$ indicates an improved restraint effect.

As shown in Figure 29, the variation law of $\Delta Q$ after the foundation pit excavation and building loading was consistent. When the elevation of the isolation pile top was above the tunnel structure roof, the restraint effects of the isolation piles on the increasing trend in shear force of the tunnel structure slightly differed. When the elevation of the isolation pile top was below the tunnel structure roof, the restraint effect of the isolation piles decreased gradually.

Similar to the reinforcement effect law of tunnel structure displacement, the bending moments and shear forces of the transverse tunnel structure were smaller than those without isolation piles. When the top of the isolation pile was above the depth of the tunnel roof, and the restraint effects of the isolation piles on the increasing trend of the bending moment and shear force were similar, and when the isolation pile top was below the depth of the tunnel roof, the restraint effect of the isolation piles on the increasing trend of the bending moment and shear force was evidently weakened. With the increase in the buried depth of the pile top, the normal force of the tunnel structure gradually 
increased, and the restraint effect of the isolation piles on the increasing trend in normal force of the tunnel structure gradually weakened.

\subsection{Influence of Burial Depth of the Isolation Pile Bottom on Reinforcement Effects}

5.2.1. Analysis of Control Effects on Tunnel Structure Displacement. The burial depth of the pile top, pile diameter, and pile spacing were $0,0.8 \mathrm{~m}$, and $2 D$, respectively, when studying the reinforcement effects of isolation piles under different burial depths of the pile bottom of $1.7 \mathrm{H}$, $1.8 \mathrm{H}, 1.9 \mathrm{H}, 2 \mathrm{H}$, and $2.1 \mathrm{H}$, as shown in Figure 30 . Table 10 shows the reinforcement effect of isolation piles on torsional deformation of the tunnel structure.

Figure 30 shows that as burial depth of the pile bottom increased, $\Delta S$ increased. The maximum horizontal displacement of the tunnel structure decreased compared with that under the condition without isolation pile reinforcement. The reinforcement effect was also gradually enhanced. Therefore, as the length of isolation piles embedded into the soil in the unaffected area increased, the displacement of the tunnel structure correspondingly decreased. However, after the length exceeded a certain value, the increasing rate of $\Delta S$ gradually decreased, and the improvement in the reinforcement effect gradually slowed down. The increase in burial depth of the pile bottom could improve the reinforcement effect on horizontal displacement of the tunnel structure but could also increase the material cost of construction.

Analysis of Table 10 indicates that the reinforcement effect of isolation piles on torsional deformation of the tunnel structure increased as the burial depth of the pile bottom increased. However, the increasing rate of the reinforcement effect gradually decreased. Therefore, the burial depth of the pile bottom should be reasonably determined in the design process, and attention should be paid to economic benefits and favorable reinforcement effects in the engineering practice.

5.2.2. Analysis of Control Effects on Internal Force of Transverse Tunnel Structure. The difference between the additional normal forces is shown in Figure 31, the difference between the additional bending moments is shown in Figure 32, and the difference between the additional shear forces is shown in Figure 33.

As shown in Figure 31, the difference between the additional normal forces $\Delta N$ under the conditions with and without isolation pile reinforcement slightly changed with the increase in the depth of the pile bottom, and the restraint effects of isolation piles on the increasing trend in normal force of the tunnel structure slightly differed.

Figure 32 shows that the value of $\Delta M$ increased gradually with the increase in the depth of the pile bottom after the foundation pit excavation. $\Delta M$ decreased with the increase in the depth of the pile bottom after the building loading. The restraint effect of the isolation piles on the increasing

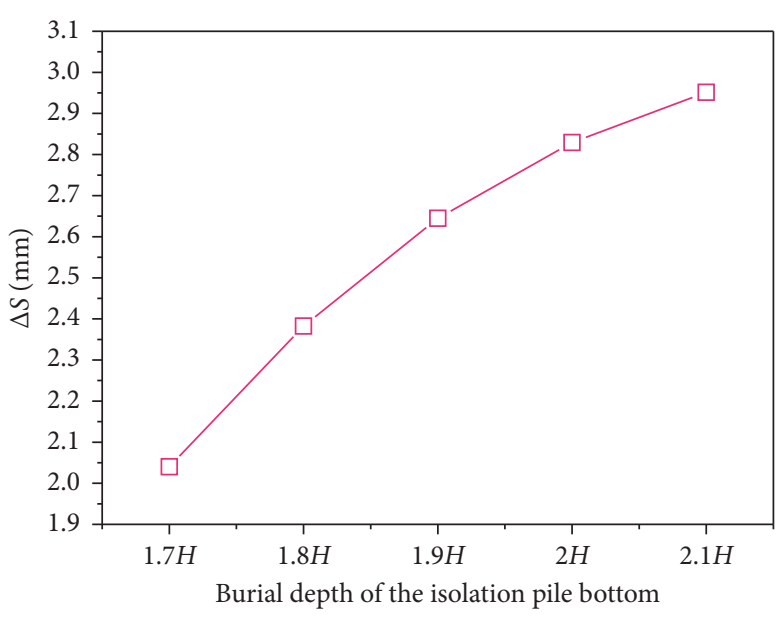

FIGURE 30: Decrement in maximum horizontal displacement of the tunnel structure under different isolation pile bottom depths.

TABLE 10: Reinforcement effects of isolation piles on torsional deformation of the tunnel structure under different isolation pile bottom depths.

\begin{tabular}{lcc}
\hline $\begin{array}{l}\text { Isolation pile } \\
\text { bottom depth }\end{array}$ & $\begin{array}{c}\beta \text { after foundation pit } \\
\text { excavation (\%) }\end{array}$ & $\begin{array}{c}\beta \text { after building } \\
\text { loading (\%) }\end{array}$ \\
\hline $1.7 H$ & 17.70 & 21.11 \\
$1.8 H$ & 22.46 & 27.24 \\
$1.9 H$ & 25.47 & 29.79 \\
$2 H$ & 27.68 & 32.18 \\
$2.1 H$ & 29.39 & 33.78 \\
\hline
\end{tabular}

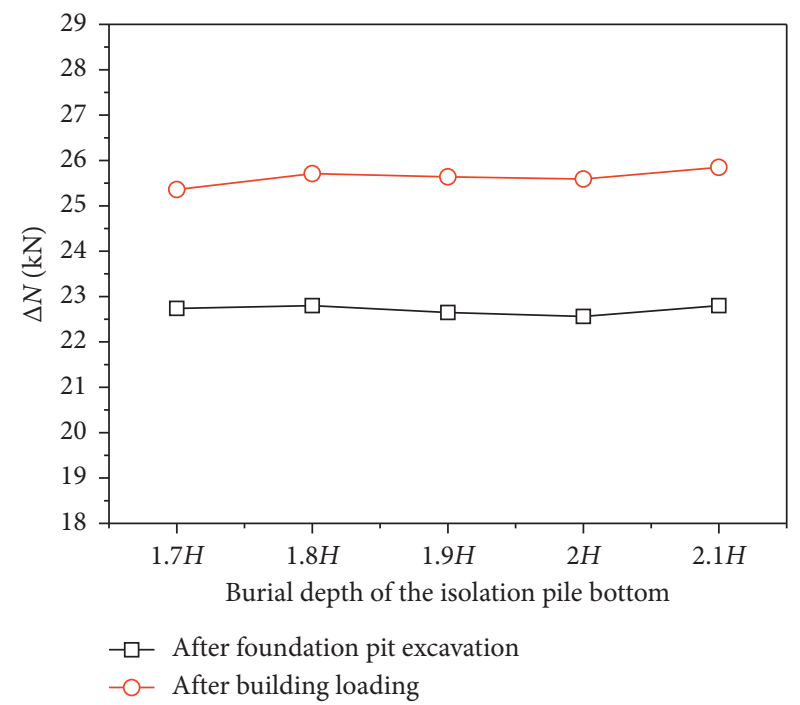

Figure 31: Difference between the additional normal forces.

trend in bending moment of the tunnel structure increased with the increase in the depth of the pile bottom.

As shown in Figure 33, $\Delta Q$ decreased gradually with the increase in the depth of the isolation pile bottom after the foundation pit excavation and building loading, and the restraint effect of the isolation piles on the increasing trend in shear force of the tunnel structure increased gradually. 


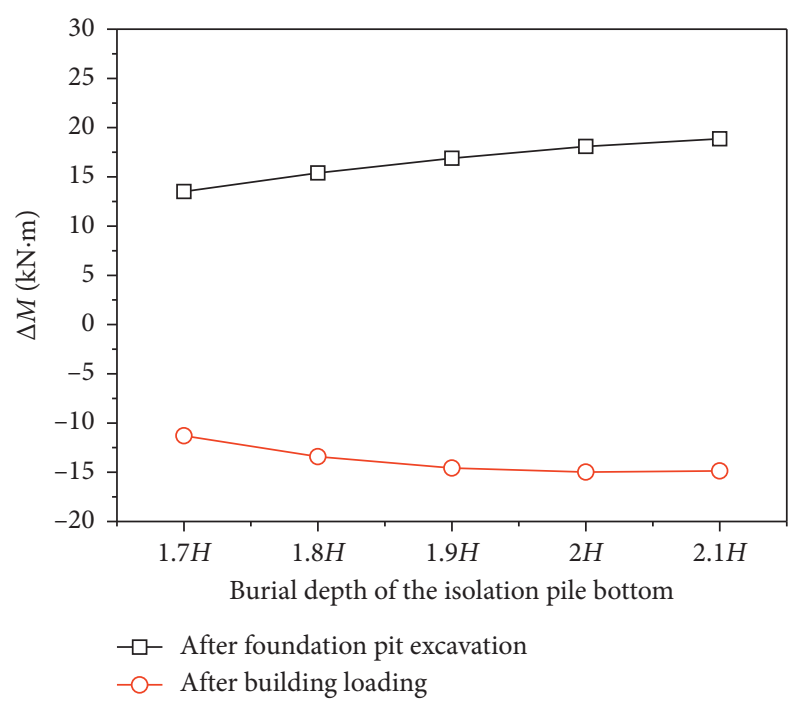

FIgURE 32: Difference between the additional bending moments.

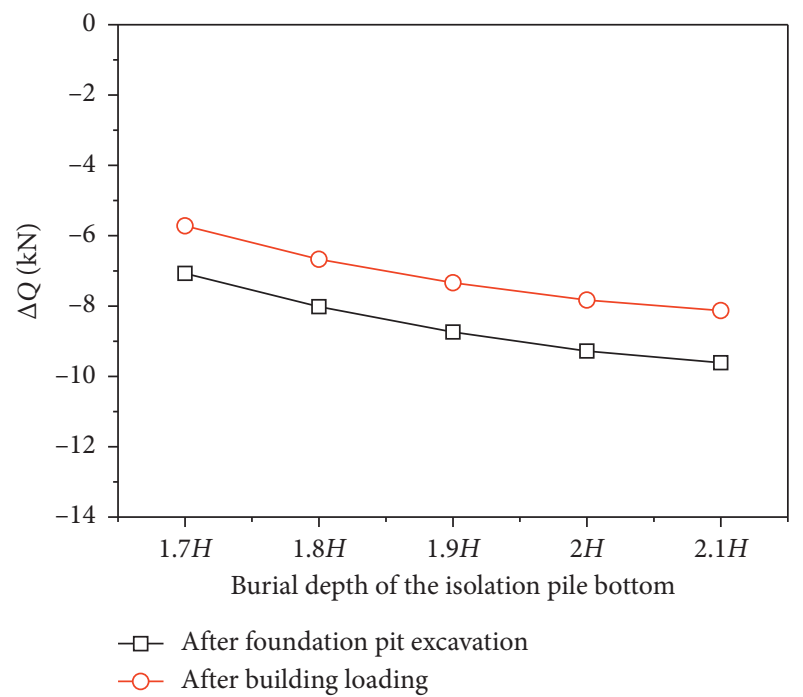

FIGURE 33: Difference between the additional shear forces.

Similar to the displacement reinforcement law of the tunnel structure, increasing the buried depth of the isolation pile bottom could improve the restraint effect on the increasing trend in bending moment and shear force of the transverse tunnel structure and could protect the safety of the tunnel structure. However, the restraint effects of isolation piles on the increasing trend in normal force of the tunnel structure slightly differed.

\subsection{Influence of Isolation Pile Spacing on Reinforcement Effects}

5.3.1. Analysis of Control Effects on Tunnel Structure Displacement. Isolation pile spacing was divided into $1 D, 2 D$, and $3 D$ to study the reinforcement effects of isolation piles under different pile spacing conditions. The burial depth of the pile top, pile diameter, and burial depth of the pile bottom were $0,0.8 \mathrm{~m}$, and $1.9 \mathrm{H}$, respectively. Figure 34 shows the results,

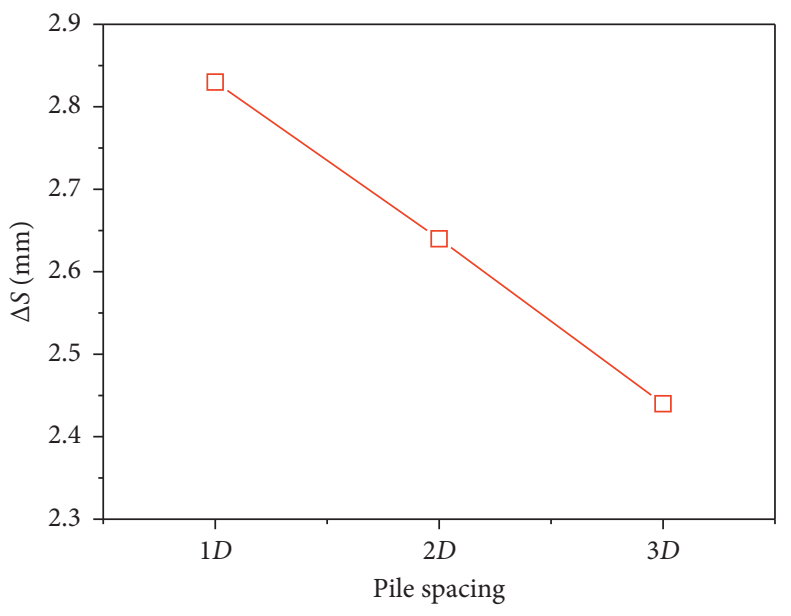

FIGURE 34: Decrement in maximum horizontal displacement of the tunnel structure under different isolation pile spacing.

and Table 11 presents the reinforcement effect of isolation piles on torsional deformation of the tunnel structure.

Figure 34 shows that when the pile spacing was $1 D$, the reinforcement effect on horizontal displacement of the tunnel structure was the best. As pile spacing increased, the limiting effect of isolation piles on soil displacement weakened. During the foundation pit excavation, displacement of the soil was large and the tunnel structure took a large displacement under the extruding effect of the soil.

Table 11 shows that, with the increase in pile spacing, the reduction ratio of the maximum horizontal displacement difference between the tunnel structure roof and the floor decreased from $28.23 \%$ to $21.43 \%$ at the completion of pit excavation and from $32.63 \%$ to $25.38 \%$ at the completion of building loading. The main reason was that the increase in pile spacing could reduce the ability of isolation piles to bear horizontal load of the soil, and the soil experienced large horizontal displacement deformation. Soil deformation had an extruding effect on the tunnel structure. Consequently, the difference in displacement between the tunnel structure roof and the floor after pit excavation and building loading increased, torsional deformation of the tunnel structure increased, and reinforcement effect of isolation piles on the tunnel structure gradually weakened. Therefore, pile spacing should be reasonably selected in actual engineering.

5.3.2. Analysis of Control Effects on Internal Force of Transverse Tunnel Structure. The difference between the additional normal forces is shown in Figure 35, the difference between the additional bending moments is shown in Figure 36, and the difference between the additional shear forces is shown in Figure 37.

Figure 35 shows that $\Delta N$ decreased gradually when the spacing of the isolation pile increased after the foundation pit excavation and building loading, and the restraint effect of isolation piles on the increasing trend in normal force of the tunnel structure decreased gradually.

As shown in Figure 36, $\Delta M$ insignificantly changed with the increase in the spacing between isolation piles after the 
TABLE 11: Reinforcement effects of isolation piles on torsional deformation of the tunnel structure under different isolation pile spacing.

\begin{tabular}{lcc}
\hline Pile spacing & $\begin{array}{c}\beta \text { after foundation pit } \\
\text { excavation (\%) }\end{array}$ & $\begin{array}{c}\beta \text { after building } \\
\text { loading (\%) }\end{array}$ \\
\hline $1 D$ & 28.23 & 32.63 \\
$2 D$ & 25.47 & 29.79 \\
$3 D$ & 21.43 & 25.38 \\
\hline
\end{tabular}

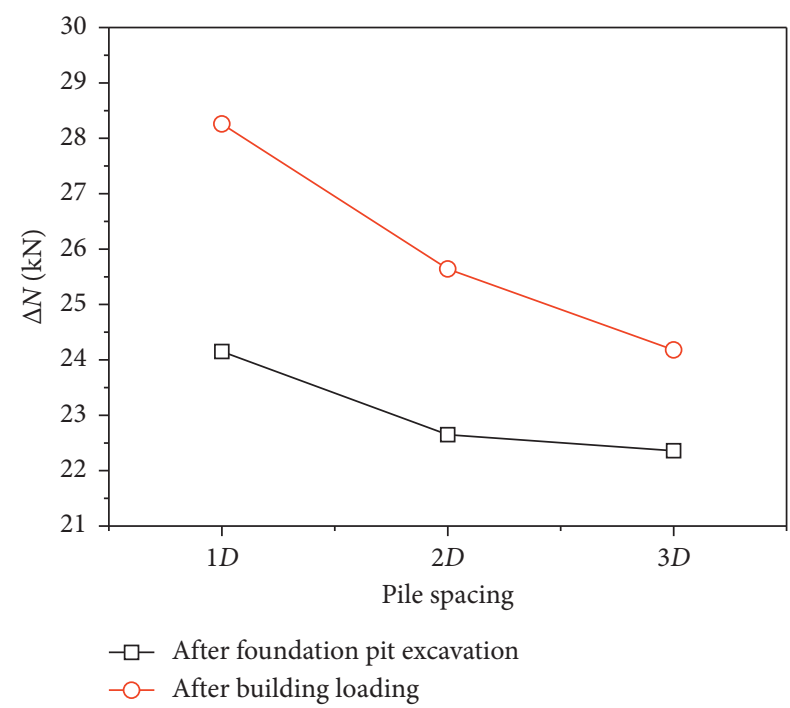

Figure 35: Difference between the additional normal forces.

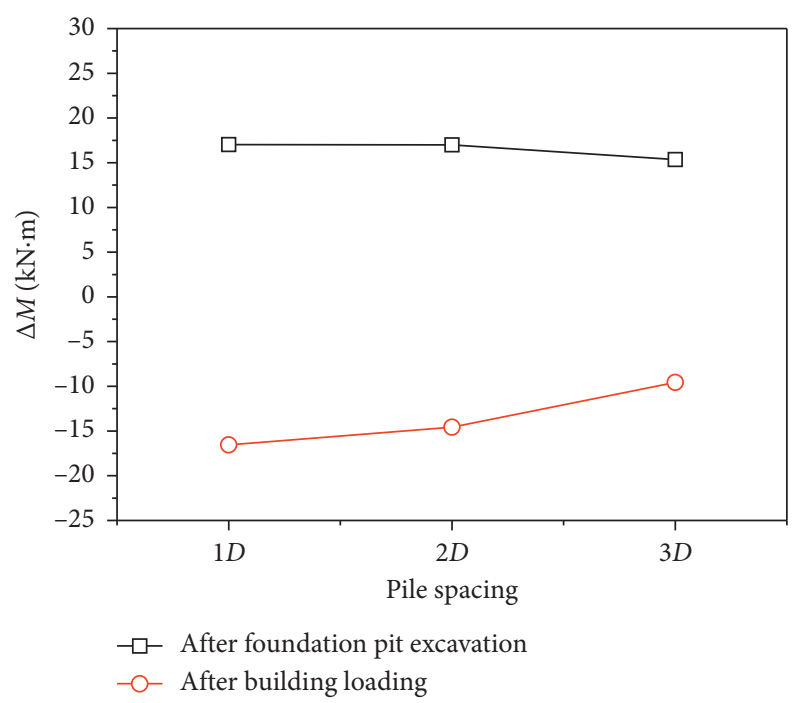

Figure 36: Difference between the additional bending moments.

foundation pit excavation. By contrast, $\Delta M$ increased slightly after the building loading. The restraint effect of the isolation piles on the increasing trend in bending moment of the tunnel structure decreased accordingly.

Figure 37 shows that $\Delta Q$ increased gradually with the increase in the spacing between isolation piles after the foundation pit excavation and building loading, and the

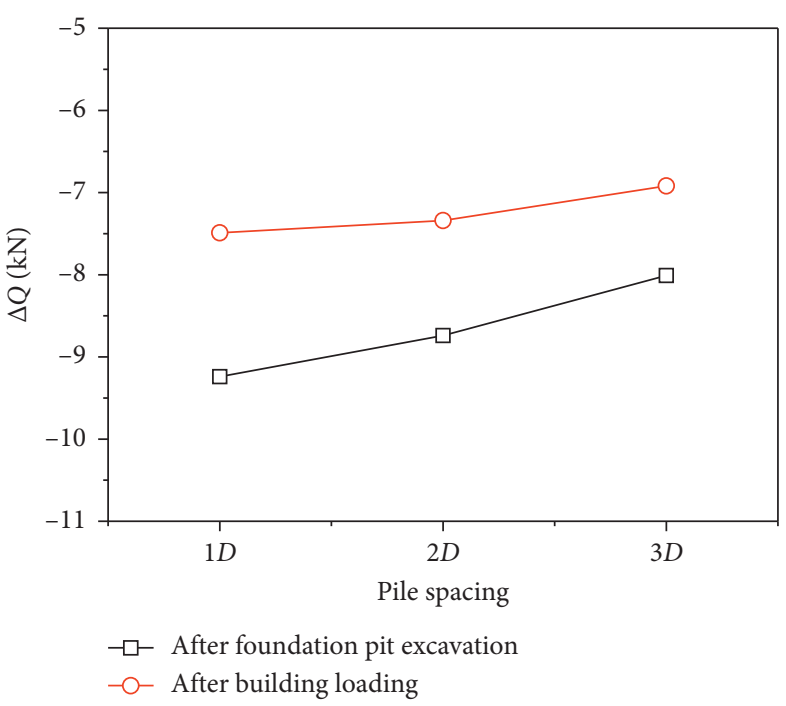

FIGURE 37: Difference between the additional shear forces.

restraint effect of the isolation piles on the increasing trend in shear force of the tunnel structure decreased gradually.

From the above analysis, it can be concluded that when the spacing of isolation piles increased, the restraint effect of the isolation piles on the increasing trend in internal forces of the transverse tunnel structure decreased correspondingly. This was similar to that of the displacement reinforcement law of the tunnel structure.

\subsection{Influence of Isolation Pile Diameter on Reinforcement Effects}

5.4.1. Analysis of Control Effects on Tunnel Structure Displacement. Increasing the diameter of isolation piles could increase the flexural rigidity and compressive rigidity of the piles. Therefore, the piles with a diameter of $0.8 \mathrm{~m}, 1 \mathrm{~m}$, and $1.2 \mathrm{~m}$ were selected for analysis.

The burial depth of the pile top, pile spacing, and depth of the pile bottom were $0,1.6 \mathrm{~m}$, and $1.9 \mathrm{H}$, respectively. Figure 38 shows the results, and Table 12 presents the reinforcement effect of isolation piles on torsional deformation of the tunnel structure.

Figure 38 shows that $\Delta S$ increased as pile diameter increased. Therefore, as the diameter of isolation piles increased, the displacement of the tunnel structure correspondingly decreased. Increasing the diameter of isolation piles could better restrict the displacement of soil and then reduce the horizontal displacement of the tunnel structure.

Table 12 shows that, with the increase in pile diameter, the reduction ratio of the maximum horizontal displacement difference between the tunnel structure roof and the floor increased from $25.47 \%$ to $40.48 \%$ at the completion of pit excavation and from $29.79 \%$ to $45.62 \%$ at the completion of building loading.

This shows that the ability of isolation piles to bear horizontal load increased with the increase of pile diameter, namely, the increase of pile rigidity. When the pile rigidity was large, the horizontal displacement of soil decreased in 


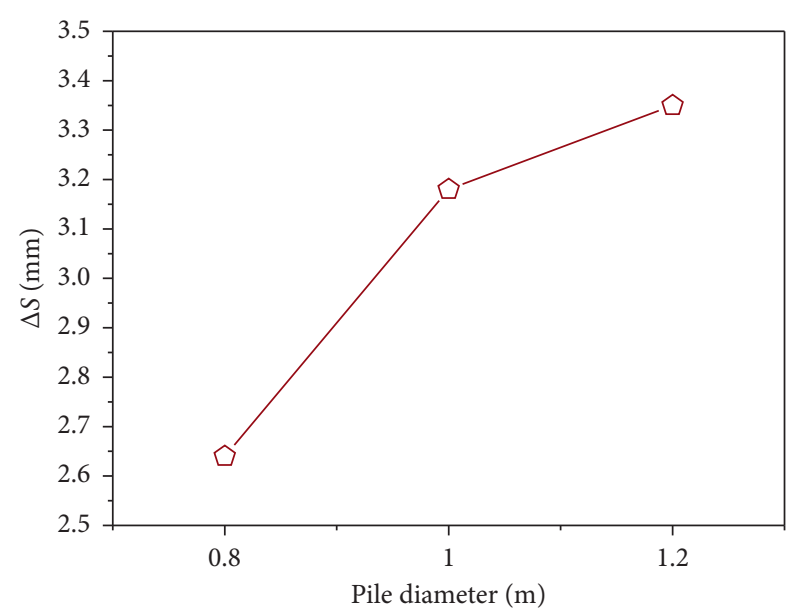

FIGURE 38: Decrement in maximum horizontal displacement of the tunnel structure under different isolation pile diameters.

TABLE 12: Reinforcement effects of isolation piles on torsional deformation of the tunnel structure under different isolation pile diameters.

\begin{tabular}{lcc}
\hline Pile diameter $(\mathrm{m})$ & $\begin{array}{c}\beta \text { after foundation } \\
\text { pit excavation }(\%)\end{array}$ & $\begin{array}{c}\beta \text { after building } \\
\text { loading }(\%)\end{array}$ \\
\hline 0.8 & 25.47 & 29.79 \\
1 & 36.39 & 41.39 \\
1.2 & 40.48 & 45.62 \\
\hline
\end{tabular}

foundation pit excavation and building load processes. The extruding effect of soil on the tunnel structure and the torsional deformation of the tunnel structure decreased correspondingly.

5.4.2. Analysis of Control Effects on Internal Force of Transverse Tunnel Structure. The difference between the additional normal forces is shown in Figure 39, the difference between the additional bending moments is shown in Figure 40, and the difference between the additional shear forces is shown in Figure 41.

Figure 39 shows that $\Delta N$ increased gradually when the pile diameter increased after the foundation pit excavation and building loading, and the restraint effect of isolation piles on the increasing trend in normal force of the tunnel structure increased gradually.

As shown in Figure 40, $\Delta M$ insignificantly changed with the increase in the pile diameter after the foundation pit excavation, and $\Delta M$ decreased slightly after the building loading. The restraint effect of isolation piles on the increasing trend in bending moment of the tunnel structure increased accordingly.

As shown in Figure 41, $\Delta Q$ changed slightly with the increase in pile diameter, and the restraint effects of isolation piles on the increasing trend in shear force of the tunnel structure slightly differed.

From the above analysis, it can be concluded that increasing the rigidity of isolation piles could improve the restraint effect of the isolation piles on the increase in normal force and bending moment of the tunnel structure.

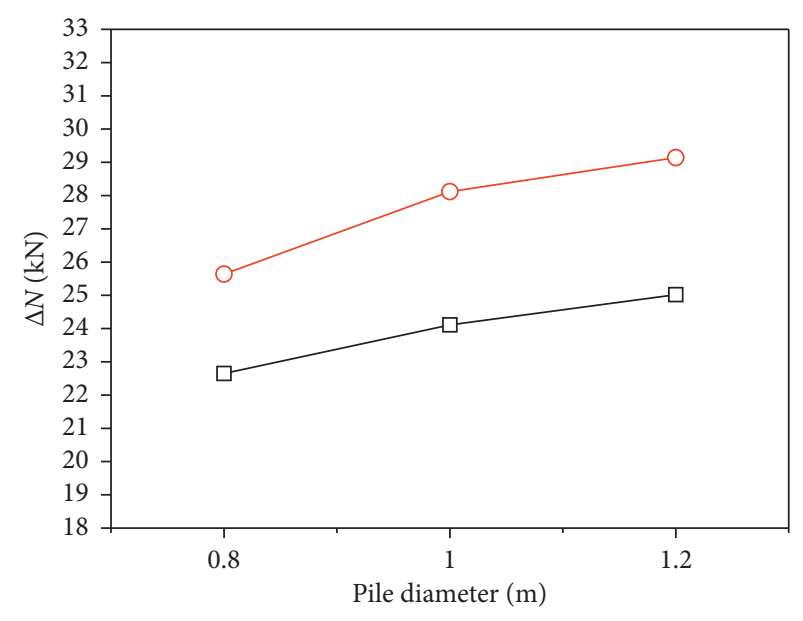

$-\square-$ After foundation pit excavation

- - - After building loading

Figure 39: Difference between the additional normal forces.

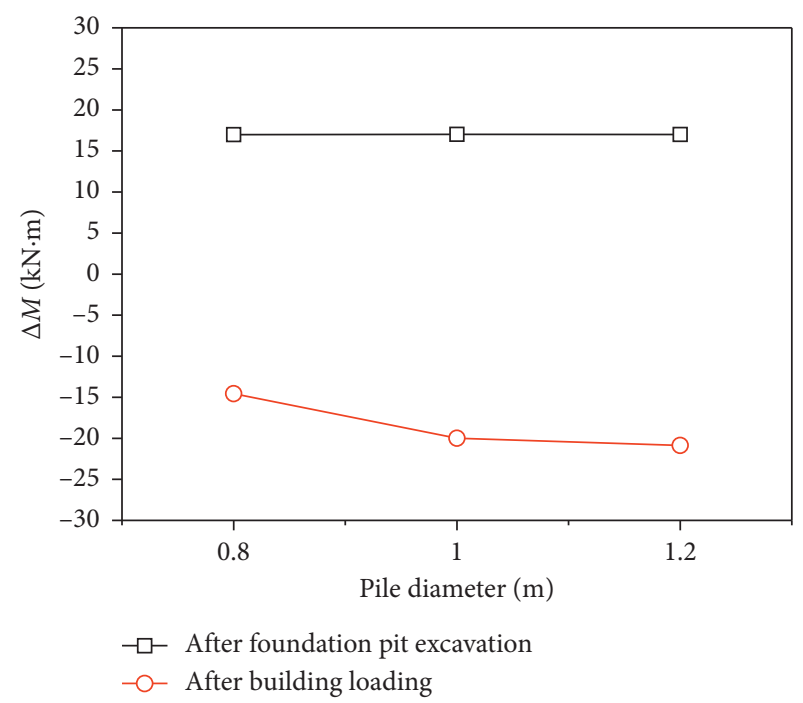

FIGURE 40: Difference between the additional bending moments.

However, the restraint effects of isolation piles on the increasing trend in shear force of the tunnel structure slightly differed.

\section{Orthogonal Experiment Analysis of Influencing Factors}

6.1. Orthogonal Experiment Design. In actual engineering, the isolation pile spacing, pile diameter, and burial depths of the pile top and bottom influence the reinforcement effect. In this study, the orthogonal experiment method of numerical simulation was used to analyze the reinforcement effects of isolation piles under the influence of four factors. Table 13 shows the influencing factors and levels based on the analysis results obtained in Section 5 .

Given that four factors and three levels were considered, an $\mathrm{L}_{9}\left(3^{4}\right)$ orthogonal experiment table was used. Table 14 


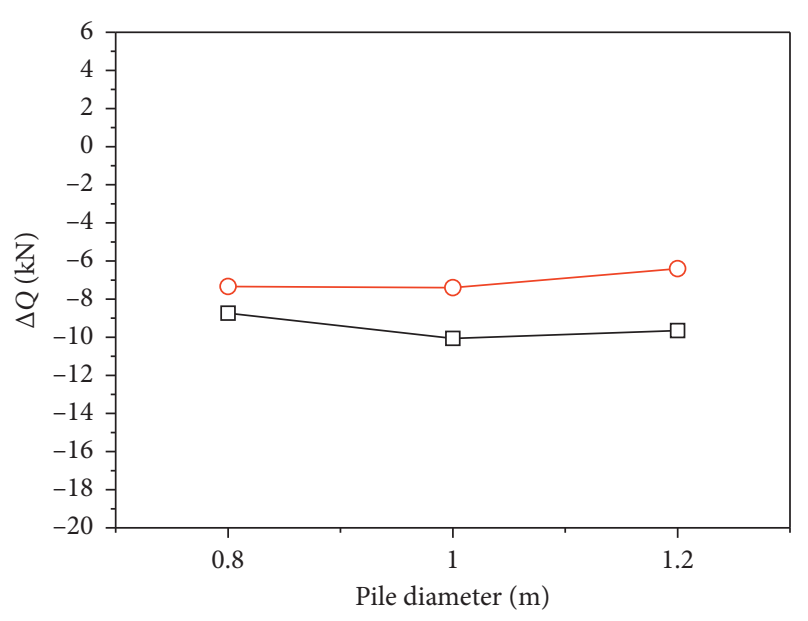

$\neg-$ After foundation pit excavation

-○- After building loading

FIGURE 41: Difference between the additional shear forces.

TABLE 13: Influencing factors and levels.

\begin{tabular}{lccc}
\hline Influencing factors & Level 1 & Level 2 & Level 3 \\
\hline Pile bottom depth (A) & $1.8 H$ & $1.9 H$ & $2 \mathrm{H}$ \\
Pile top depth (B) & $0.5 Z$ & $0.625 Z$ & $0.75 Z$ \\
Pile spacing (C) & $1.6 \mathrm{~m}$ & $2.4 \mathrm{~m}$ & $3.2 \mathrm{~m}$ \\
Pile diameter (E) & $0.8 \mathrm{~m}$ & $1 \mathrm{~m}$ & $1.2 \mathrm{~m}$ \\
\hline
\end{tabular}

TABLE 14: Orthogonal experiment scheme of the numerical simulation.

\begin{tabular}{lcccc}
\hline $\begin{array}{l}\text { Scheme } \\
\text { number }\end{array}$ & $\begin{array}{c}\text { Pile bottom } \\
\text { depth (A) }\end{array}$ & $\begin{array}{c}\text { Pile top } \\
\text { depth (B) }\end{array}$ & $\begin{array}{c}\text { Pile } \\
\text { spacing }(\mathrm{C})\end{array}$ & $\begin{array}{c}\text { Pile } \\
\text { diameter }(E)\end{array}$ \\
\hline 1 & $1.8 H$ & $0.5 Z$ & 1.6 & 0.8 \\
2 & $1.8 H$ & $0.625 Z$ & 2.4 & 1 \\
3 & $1.8 H$ & $0.75 Z$ & 3.2 & 1.2 \\
4 & $1.9 H$ & $0.5 Z$ & 2.4 & 1.2 \\
5 & $1.9 H$ & $0.625 Z$ & 3.2 & 0.8 \\
6 & $1.9 H$ & $0.75 Z$ & 1.6 & 1 \\
7 & $2 H$ & $0.5 Z$ & 3.2 & 1 \\
8 & $2 H$ & $0.625 Z$ & 1.6 & 1.2 \\
9 & $2 H$ & $0.75 Z$ & 2.4 & 0.8 \\
\hline
\end{tabular}

shows the orthogonal experiment scheme of the numerical simulation.

6.2. Analysis of Orthogonal Experiment Results. Numerical simulation analysis of the experiment scheme in Table 14 was carried out. In actual engineering, the influence of building construction on the adjacent existing tunnel structure was mainly evaluated by the displacement of the tunnel structure. Therefore, $\Delta S$ and $\beta$ were selected as indexes to analyze the influence of different factors of isolation piles on the reinforcement effect on the tunnel structure, and a reasonable reinforcement scheme of isolation piles was given. Table 15 shows the obtained results.
TABLE 15: Orthogonal experiment results of the numerical simulation.

\begin{tabular}{lccc}
\hline $\begin{array}{l}\text { Scheme } \\
\text { number }\end{array}$ & $\Delta S(\mathrm{~mm})$ & $\begin{array}{c}\beta \text { after foundation pit } \\
\text { excavation (\%) }\end{array}$ & $\begin{array}{c}\beta \text { after building } \\
\text { loading }(\%)\end{array}$ \\
\hline 1 & 2.38 & 22.41 & 28.15 \\
2 & 2.42 & 26.27 & 31.97 \\
3 & 2.56 & 26.99 & 31.23 \\
4 & 2.97 & 34.86 & 40.99 \\
5 & 2.33 & 19.65 & 24.56 \\
6 & 3.10 & 33.48 & 37.08 \\
7 & 2.99 & 32.25 & 37.22 \\
8 & 3.61 & 44.63 & 49.46 \\
9 & 2.76 & 25.55 & 29.77 \\
\hline
\end{tabular}

Table 16 shows the calculated average value $K_{i}$ of $\Delta S$ and $\beta$ at each factor and level. The range $R$ is the difference between the maximum and minimum average values of the index under the condition of each level of each factor. $R$ represents the change range of the indexes when the levels of factors change. A large $R$ value of a factor indicates that it has a large influence on the index.

On the basis of the analysis of Table 16, the influence degrees of influencing factors of the reinforcement effect of isolation piles from high to low were sorted as follows: pile diameter, burial depth of the pile bottom, pile spacing, and burial depth of the pile top. The reduction in pile spacing could improve the reinforcement effect of isolation piles, and the optimal pile spacing was $1.6 \mathrm{~m}$. Within a certain scope, the increase in burial depth of the pile top slightly influenced the reinforcement effect, and the optimal burial depth of the pile top was $0.75 Z$. The increase in burial depth of the pile bottom would increase the pile length embedded in the stable soil layer outside the affected area of foundation pit excavation. As a result, the reinforcement effect of isolation piles on the existing tunnel structure was improved, and the optimal burial depth of the pile bottom was $2 H$. The increase in pile diameter considerably improved the reinforcement effect of isolation piles, and the optimal pile diameter was $1.2 \mathrm{~m}$.

\section{Conclusions}

Numerical simulation and similar material model test methods were used in this study to investigate building construction adjacent to the existing subway tunnel under the condition with isolation pile reinforcement. The reinforcement effects of isolation piles under the influence of different factors were obtained. The main conclusions were obtained as follows:

(1) In the process of foundation pit excavation and building loading, deformation laws of the tunnel structure with isolation pile reinforcement were similar to those under the condition without isolation pile reinforcement. The tunnel structure first experienced displacement toward the foundation pit, and this displacement slightly recovered in the building loading phase; however, torsional deformation of the tunnel structure toward the 
TABLE 16: Influences of different factors on target.

\begin{tabular}{|c|c|c|c|c|c|c|c|c|c|c|c|c|}
\hline \multirow{2}{*}{ Level } & \multicolumn{4}{|c|}{$\Delta S(\mathrm{~mm})$} & \multicolumn{4}{|c|}{$\beta$ after foundation pit excavation (\%) } & \multicolumn{4}{|c|}{$\beta$ after building loading (\%) } \\
\hline & $K_{\mathrm{A}}$ & $K_{\mathrm{B}}$ & $K_{\mathrm{C}}$ & $K_{\mathrm{E}}$ & $K_{\mathrm{A}}$ & $K_{\mathrm{B}}$ & $K_{\mathrm{C}}$ & $K_{\mathrm{E}}$ & $K_{\mathrm{A}}$ & $K_{\mathrm{B}}$ & $K_{\mathrm{C}}$ & $K_{\mathrm{E}}$ \\
\hline 1 & 2.46 & 2.78 & 3.03 & 2.49 & 25.23 & 29.84 & 33.51 & 22.54 & 30.45 & 35.45 & 38.23 & 27.49 \\
\hline 2 & 2.80 & 2.79 & 2.72 & 2.84 & 29.33 & 30.18 & 28.89 & 30.67 & 34.21 & 35.33 & 34.24 & 35.42 \\
\hline 3 & 3.12 & 2.81 & 2.62 & 3.05 & 34.14 & 28.67 & 26.30 & 35.49 & 38.82 & 32.69 & 31.00 & 40.56 \\
\hline$R$ & 0.66 & 0.03 & 0.41 & 0.56 & 5.91 & 1.51 & 7.21 & 12.95 & 8.37 & 2.76 & 7.23 & 13.07 \\
\hline
\end{tabular}

foundation pit kept increasing. The internal force of the transverse tunnel structure also increased generally, and there was little difference between the internal forces of the transverse tunnel structure after foundation pit excavation and building loading. Under the condition of isolation pile reinforcement in the building construction, maximum horizontal displacement of the adjacent existing tunnel structure and differences in horizontal displacement between the tunnel structure roof and the floor were decreased. The horizontal displacement and torsional deformation of the tunnel structure toward the foundation pit were controlled. The increasing trend of internal forces in the transverse tunnel structure had been restrained to varying degrees, and disaster risk of the tunnel structure in the adjacent building construction was decreased.

(2) Above the burial depth of the tunnel structure roof, the increase in burial depth of the isolation pile top slightly influenced the reinforcement effect on deformation of the tunnel structure, the restraint effects on the increasing trend of shear force and bending moment of the transverse tunnel structure slightly differed, and the restraint effect on the increasing trend of normal force gradually weakened. The reinforcement effect of isolation piles on the tunnel structure was enhanced as burial depth of the pile bottom increased. However, the increasing rate of the reinforcement effect gradually decreased. Increasing the buried depth of the isolation pile bottom could improve the restraint effect on the increasing trend of bending moment and shear force of the transverse tunnel structure and could protect the safety of the tunnel structure. However, the restraint effects on the normal force of the tunnel structure slightly differed. Therefore, the burial depth of the pile bottom should be properly increased to improve the reinforcement effect. As isolation pile spacing increased, the reinforcement effect on the tunnel structure decreased. Therefore, pile spacing should be reasonably selected in the engineering practice to guarantee favorable reinforcement effects. Increasing the isolation pile diameter could improve the reinforcement effect on the displacement of the tunnel structure, and the restraint effect of isolation piles on the increase of normal force and bending moment of the tunnel structure was gradually enhanced. However, the restraint effects on the increasing trend in shear force of the tunnel structure slightly differed.
(3) The building process under four factors of isolation pile spacing, pile diameter, bottom depth, and top depth was analyzed by the orthogonal experiment using the numerical simulation method. The influence degrees of four factors on the reinforcement effect were obtained and sorted from high to low as follows: pile diameter, bottom depth, pile spacing, and top depth. The optimal parameter values of the four factors were $1.2 \mathrm{~m}, 2 \mathrm{H}, 1.6 \mathrm{~m}$, and $0.75 \mathrm{Z}$.

(4) The reinforcement effect of isolation piles on the existing shield tunnel in the adjacent building construction process was studied. The obtained conclusions could provide a corresponding reference for similar projects. However, this study did not investigate the reinforcement effects of isolation piles under different relative positions of the building on the existing shield tunnel. Moreover, the connection of tunnel lining segments in the model test should be further refined in the future test. These aspects should be studied in the future.

\section{Data Availability}

The data used to support the findings of this study are available from the corresponding author upon request.

\section{Conflicts of Interest}

The authors declare that they have no conflicts of interest.

\section{Acknowledgments}

This work was supported by the National Natural Science Foundation of China (nos. 51578023 and 51538001).

\section{References}

[1] J. Y. Han, W. Zhao, P. J. Jia, Y. P. Guan, Y. Chen, and B. F. Jiang, "Risk analysis of the opening of shield-tunnel circumferential joints induced by adjacent deep excavation," Journal of Performance of Constructed Facilities, vol. 32, no. 1, Article ID 04017123, 2018.

[2] R. Liang, W. Wu, F. Yu, G. Jiang, and J. Liu, "Simplified method for evaluating shield tunnel deformation due to adjacent excavation," Tunnelling and Underground Space Technology, vol. 71, pp. 94-105, 2018.

[3] Z. Zhang, M. Huang, and W. Wang, "Evaluation of deformation response for adjacent tunnels due to soil unloading in excavation engineering," Tunnelling and Underground Space Technology, vol. 38, pp. 244-253, 2013. 
[4] G. Zheng, X. Yang, H. Zhou, Y. Du, J. Sun, and X. Yu, “A simplified prediction method for evaluating tunnel displacement induced by laterally adjacent excavations," Computers and Geotechnics, vol. 95, pp. 119-128, 2018.

[5] J.-F. Zhang, J.-J. Chen, J.-H. Wang, and Y.-F. Zhu, "Prediction of tunnel displacement induced by adjacent excavation in soft soil," Tunnelling and Underground Space Technology, vol. 36, pp. 24-33, 2013.

[6] M.-G. Li, X. Xiao, J.-H. Wang, and J.-J. Chen, "Numerical study on responses of an existing metro line to staged deep excavations," Tunnelling and Underground Space Technology, vol. 85, pp. 268-281, 2019.

[7] G. Zheng and S.-W. Wei, "Numerical analyses of influence of overlying pit excavation on existing tunnels," Journal of Central South University of Technology, vol. 15, no. S2, pp. 69-75, 2008.

[8] M. Doležalová, "Tunnel complex unloaded by a deep excavation," Computers and Geotechnics, vol. 28, no. 6-7, pp. 469-493, 2001.

[9] G. Zheng, Y. Du, X. Cheng, Y. Diao, X. Deng, and F. Wang, "Characteristics and prediction methods for tunnel deformations induced by excavations," Geomechanics and Engineering, vol. 12, no. 3, pp. 361-397, 2017.

[10] J. Shi, Z. Fu, and W. Guo, "Investigation of geometric effects on three-dimensional tunnel deformation mechanisms due to basement excavation," Computers and Geotechnics, vol. 106, pp. 108-116, 2019.

[11] Y. Tan, X. Li, Z. J. Kang et al., "Zoned excavation of an oversized pit close to an existing metro line in stiff clay: case study," Journal of Performance of Constructed Facilities, vol. 29, no. 6, Article ID 04014158, 2015.

[12] X. Huang, H. F. Schweiger, and H. Huang, "Influence of deep excavations on nearby existing tunnels," International Journal of Geomechanics, vol. 13, no. 2, pp. 170-180, 2013.

[13] C. W. W. Ng, J. Shi, D. Mašín, H. Sun, and G. H. Lei, "Influence of sand density and retaining wall stiffness on threedimensional responses of tunnel to basement excavation," Canadian Geotechnical Journal, vol. 52, no. 11, pp. 1811-1829, 2015.

[14] M.-G. Li, J.-J. Chen, J.-H. Wang, and Y.-F. Zhu, "Comparative study of construction methods for deep excavations above shield tunnels," Tunnelling and Underground Space Technology, vol. 71, pp. 329-339, 2018.

[15] W. D. Wang, J. B. Wu, and Q. P. Weng, "Numerical modeling of affection of foundation pit excavation on metro tunnel," Rock and Soil Mechanics, vol. 25, no. S1, pp. 251-255, 2004.

[16] X. X. Yao, H. J. Yu, Q. G. Wang, and C. Wang, "Deformation control of operating tunnels induced by deep excavation of overlying metro," Chinese Journal of Geotechnical Engineering, vol. 36, no. 1, pp. 88-97, 2014.

[17] R. Chen, F. Meng, Z. Li, Y. Ye, and J. Ye, "Investigation of response of metro tunnels due to adjacent large excavation and protective measures in soft soils," Tunnelling and Underground Space Technology, vol. 58, pp. 224-235, 2016.

[18] J. Shi, X. Zhang, Y. Chen, and L. Chen, "Numerical parametric study of countermeasures to alleviate basement excavation effects on an existing tunnel," Tunnelling and Underground Space Technology, vol. 72, pp. 145-153, 2018.

[19] G. Zheng, H. H. Zhu, X. R. Liu et al., "Control of safety of deep excavations and underground engineering and its impact on surrounding environment," China Civil Engineering Journal, vol. 49, no. 6, pp. 1-24, 2016.

[20] M. X. Zhu, L. Wang, and W. M. Gong, "Factors influencing isolation effects of isolation piles under side loading," Chinese
Journal of Geotechnical Engineering, vol. 36, no. 4, pp. 671679, 2014.

[21] O. Demeijer, J. J. Chen, M. G. Li et al., "Influence of passively loaded piles on excavation-induced diaphragm wall displacements and ground settlements," International Journal of Geomechanics, vol. 18, no. 6, 2018.

[22] Y. Y. Xiang, S. H. He, M. Zhang et al., "Constraint effect of pilot-drift and separation-pile structure on ground movements induced by shallow tunneling," Chinese Journal of Rock Mechanics and Engineering, vol. 23, no. 19, pp. 3317-3323, 2004.

[23] G. Lin, T. Zhu, and B. Lin, "Similarity technique for dynamic structural model test," Journal of Dalian University of Technology, vol. 40, no. 1, pp. 1-8, 2000.

[24] H. Zhuang, J. Fu, X. Yu, S. Chen, and X. Cai, "Earthquake responses of a base-isolated structure on a multi-layered soft soil foundation by using shaking table tests," Engineering Structures, vol. 179, no. 15, pp. 79-91, 2019.

[25] P. L. Teo and K. S. Wong, "Application of the hardening soil model in deep excavation analysis," The IES Journal Part A: Civil \& Structural Engineering, vol. 5, no. 3, pp. 152-165, 2012. 


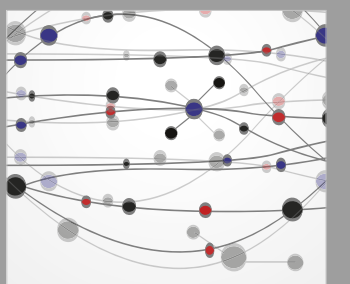

The Scientific World Journal
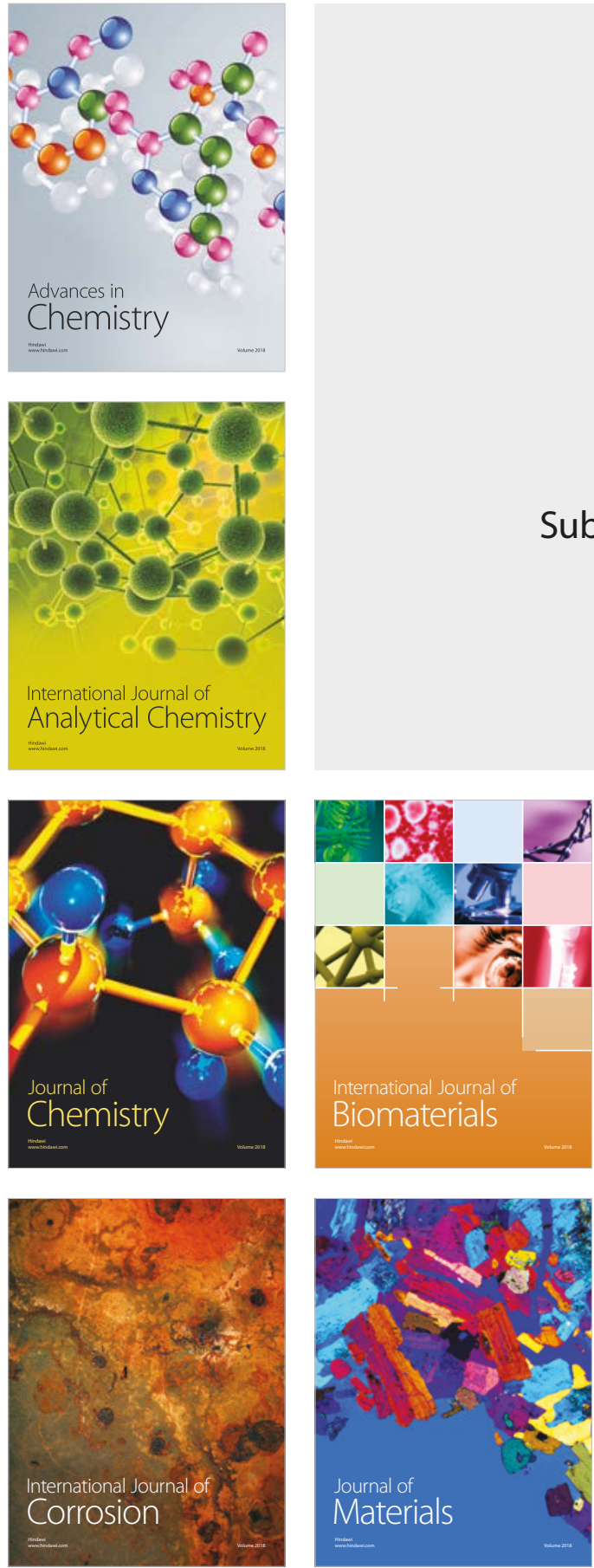

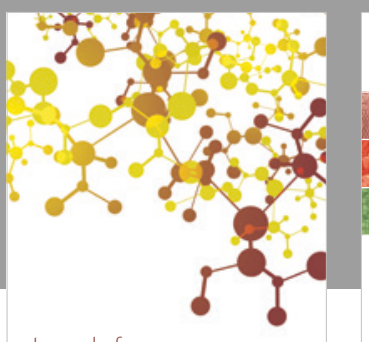

Journal of

Applied Chemistry
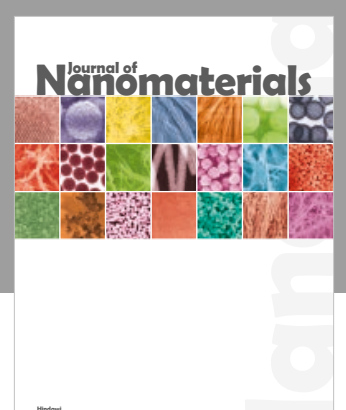

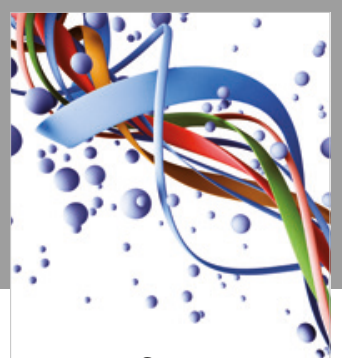

Scientifica

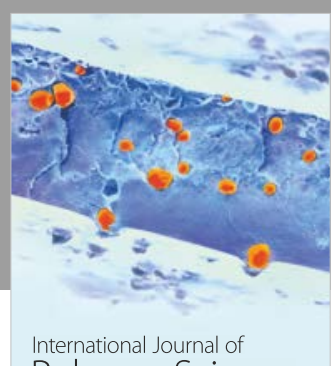

Polymer Science

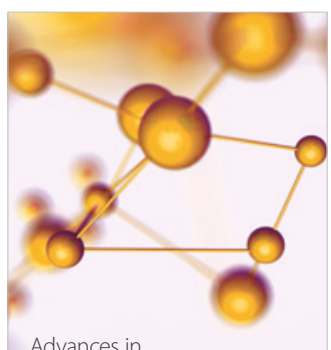

Physical Chemistry
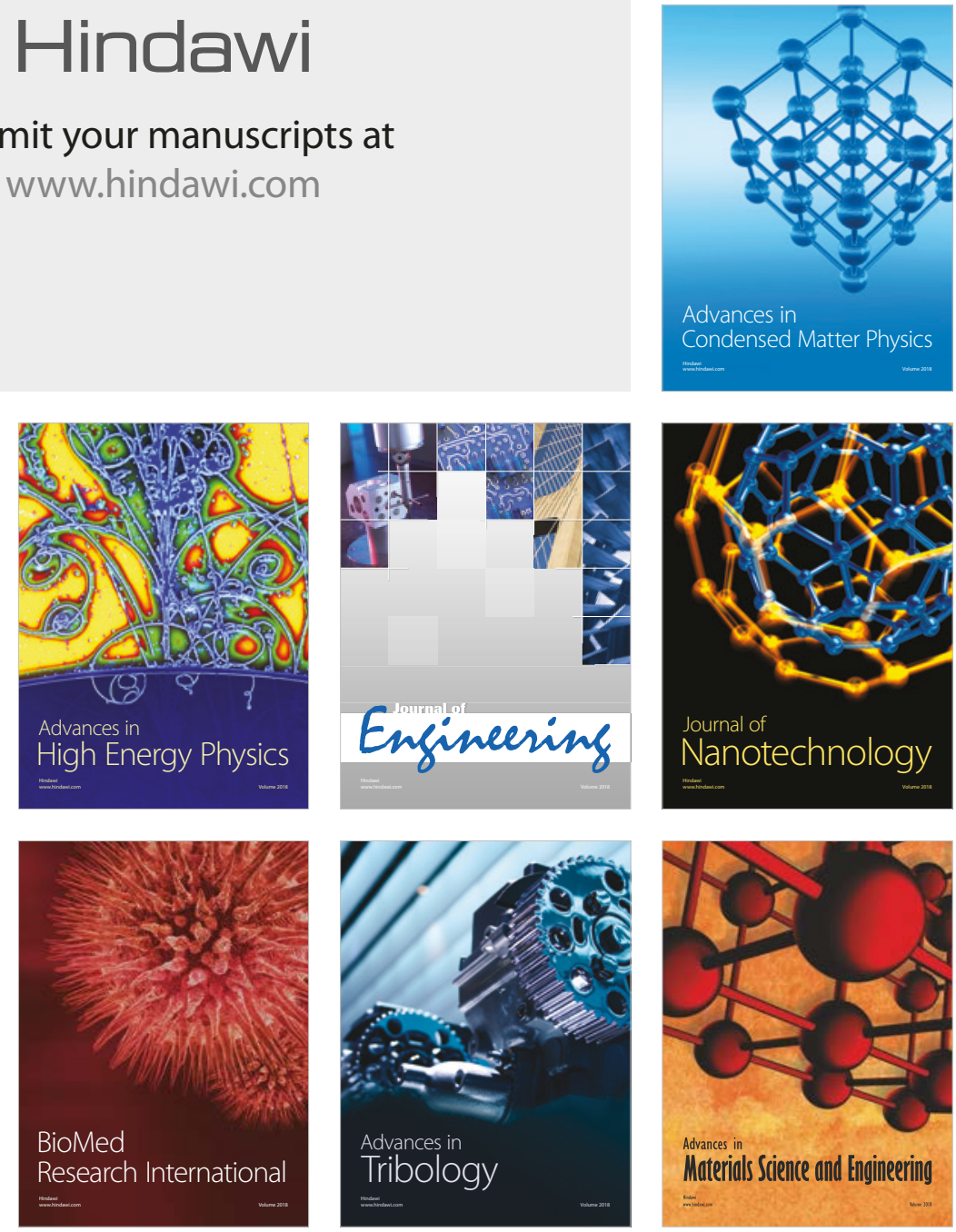